\title{
The Toxicology Investigators Consortium 2020 Annual Report
}

\author{
Meghan B. Spyres ${ }^{1,2} \cdot$ Kim Aldy $^{3,4} \cdot$ Lynn A Farrugia $^{5} \cdot$ A. Min Kang ${ }^{2,6} \cdot$ Jennifer S. Love ${ }^{7} \cdot$ Sharan L. Campleman ${ }^{4}$. \\ Shao $\mathrm{Li}^{4}$. Alexandra Amaducci ${ }^{8}$. Evan Schwarz ${ }^{9}$. Paul M. Wax ${ }^{3,4} \cdot$ Jeffery Brent ${ }^{10} \cdot$ On behalf of the Toxicology \\ Investigators Consortium Study Group
}

Received: 24 June 2021 / Revised: 13 July 2021 / Accepted: 19 July 2021 / Published online: 17 September 2021

(C) American College of Medical Toxicology 2021

\begin{abstract}
The Toxicology Investigators Consortium (ToxIC) Registry was established by the American College of Medical Toxicology in 2010. The registry collects data from participating sites with the agreement that all bedside and telehealth medical toxicology consultation will be entered. This eleventh annual report summarizes the Registry's 2020 data and activity with its additional 6668 cases. Cases were identified for inclusion in this report by a query of the ToxIC database for any case entered from January 1 to December 31, 2020. Detailed data was collected from these cases and aggregated to provide information which included demographics, reason for medical toxicology evaluation, agent and agent class, clinical signs and symptoms, treatments and antidotes administered, mortality, and whether life support was withdrawn. Gender distribution included $50.6 \%$ cases in females, $48.4 \%$ in males, and $1.0 \%$ identifying as transgender. Non-opioid analgesics were the most commonly reported agent class, followed by opioid and antidepressant classes. Acetaminophen was once again the most common agent reported. There were 80 fatalities, comprising $1.2 \%$ of all registry cases. Major trends in demographics and exposure characteristics remained similar to past years' reports. Sub-analyses were conducted to describe race and ethnicity demographics and exposures in the registry, telemedicine encounters, and cases related to the COVID-19 pandemic.
\end{abstract}

Keywords Poisoning $\cdot$ Overdose $\cdot$ Surveillance $\cdot$ Epidemiology $\cdot$ Medical Toxicology

\section{Introduction}

The year 2020 marked the beginning of the second decade of the Toxicology Investigators Consortium (ToxIC). It was a year marked by considerable expansion of ToxIC's activities. Our case accrual unabatedly continued, and we welcomed six new sites to the consortium.

Supervising Editor: Mark B. Mycyk, MD

Meghan B. Spyres

mspyres@gmail.com

1 Department of Emergency Medicine, University of Arizona College of Medicine-Phoenix, Phoenix, AZ, USA

2 Department of Medical Toxicology, Banner-University Medicial Center Phoenix, 1012 E Willetta Street, Fl 2, Phoenix, AZ 85006, USA

3 University of Texas Southwestern Medical School, 5323 Harry Hines Boulevard, Dallas, TX 75390, USA

4 American College of Medical Toxicology, 10645 N Tatum Blvd., Suite 200-111, Phoenix, AZ 85028, USA
Starting in 2020 ToxIC began a partnership with the US Centers for Disease Control and Prevention (CDC) Overdose Data to Action (OD2A) program. Through a data sharing agreement, ToxIC is working with our partners at OD2A to provide data on our experience with opioid and psychoactive substance toxicity. Given the uniqueness of our physician led data collection, ToxIC's patient-oriented database is

5 Hartford Hospital and University of Connecticut School of Medicine, 80 Seymour Street, Hartford, CT 06102, USA

6 Departments of Medicine and Child Health, University of Arizona College of Medicine-Phoenix, Phoenix, AZ, USA

7 Oregon Health \& Science University, 3181 SW Sam Jackson Park Rd, Portland, OR 97239, USA

8 Lehigh Valley Health Network, 2545 Schoenersville Rd, Bethlehem, PA 18017, USA

9 Department of Emergency Medicine, Washington University School of Medicine, 660 South Euclid, St Louis, MO 63110, USA

10 University of Colorado School of Medicine, 13001 E 17th Pl, Aurora, CO 80045, USA 
supplying a level of detail on adverse drug effects not generally available from alternate drug-toxicity databases. As our partnership with the CDC grows, we expect to collaborate with their overdose prevention efforts through our main Core Registry, our pediatric opioid and marijuana Sub-Registries, and our novel efforts on opioid and stimulant exposures.

In 2020 ToxIC embarked on two prospective multicenter projects in addition to the continuation of its Core Registry. These two projects are not based on bedside medical toxicology consultations and utilize their own unique data collection interface.

The first multicenter project started its initial year of a 5-year NIH-supported prospective clinical study of opioid overdoses presenting to the emergency department (NIH\# 1RO1DA037317- 02). Alex Manini, MD, Professor of Emergency Medicine at the Mt Sinai Icahn School of Medicine and a long time ToxIC collaborator, is the Principal Investigator of this project which characterizes the clinical course, patient characteristics, and in-depth toxicologic analysis of fentanyl analogs (or "fentalogs"). In the course of the Fentalog project, ToxIC is assessing the prevalence and role of fentalogs, novel psychoactive drugs, adulterants, and other substances in the clinical presentation and treatment of these patients. In a supplement to this grant, ToxIC is also partnering Mt Sinai on data collection specific to factors related to COVID-19 infections in patients with a history of opioid misuse. This is the first ToxIC project that has included comprehensive toxicological testing, utilizing liquid chromatography quadrupole time-of-flight mass spectrometry to elucidate the presence of psychoactive substances and their metabolites.

In 2020, the COVID-19 pandemic significantly altered human activity in a multitude of ways. The medical and public health communities vibrantly came to life in a way that had not been seen in a century. As these communities rose to the challenge and aggressively took action to deal with the evolving pandemic, ToxIC quickly mobilized. As we continued our data sharing agreement adopted in 2016 with the US Food and Drug Administration (FDA), new therapeutics were rapidly entering clinical practice via Emergency Use Authorizations employed in a time of unprecedented need. Simultaneously, measures taken by the lay community to prevent and combat COVID-19, such as taking hydroxychloroquine and drinking bleach, reached a concerning level. Because of our already existing data sharing agreement with the FDA and the need to expeditiously identify adverse drug events in this rapidly evolving environment, ToxIC and the FDA collaboratively implemented a real-time national toxicosurveillance project searching for adverse drug events associated with COVID19 prophylaxis or treatment. The so-called FDA ACMT COVID-19 ToxIC (FACT) Pharmacovigilance Project was organized and swiftly pressed into action. Similar to the Fentalog project above, the FACT project is not based on the ToxIC Core Registry or bedside medical toxicology consults, and data is collected through a separate mechanism and database.

In addition to the summary Core Registry data, this year we are presenting additional data on the use of telemedicine by medical toxicologists, as well as taking a closer look at race and ethnicity, and COVID-19 positive cases since the start of the pandemic.

Twelve full ToxIC publications in six separate journals were published in 2020. This is the largest number of journal publications in any year since ToxIC's inception. Sixteen ToxIC abstracts were published from both national and international meetings. These full publications and abstracts are enumerated on the ToxIC website: www.ToxICRegistry.org.

In addition to the above, the following new ToxIC research projects were proposed and initiated by ToxIC investigators in 2020:

1. Effect of activated charcoal administration on clinical outcome

2. A comparison of clinical outcomes following benzodiazepine or Z-drug toxicity

3. A comparison of hydroxyzine and diphenhydramine poisonings

4. The effect or race and ethnicity on access to opioid treatment facilities

5. Organ donation after death from a toxic exposure

6. Fomepizole use in acetaminophen poisoning

7. Epidemiology of pediatric antiepileptic drug poisoning

8. Trends in gastrointestinal decontamination after acute poisoning

9. Trends in toxicity from household cleaners and sanitizing agents

10. Toxicity of chloroquine and hydroxychloroquine

In 2020 ToxIC was supported by the NIH, FDA, CDC, and BTG International. These collaborations have been enriching for ToxIC but more importantly have provided unique networking opportunities for ToxIC investigators.

\section{Methods}

ToxIC was started on January 1, 2010, as a Case Registry [1]. That Core Registry continues today and prospectively enrolls patients presenting to participating sites. All sites agree to enter all inpatients or outpatients presenting to their site on whom a formal medical toxicology consultation was completed. ToxIC staff periodically meet with all sites to review patient accrual, obstacles to achieving full compliance with patient entry, quality assurance efforts, and ongoing project opportunities. Deidentified case information is entered into an online data collection form using the REDCap (Research 
Electronic Data Capture) platform. REDCap is a secure, web-based software platform designed as an electronic data capture tool for research studies hosted at the Vanderbilt University Health Core. REDCap provides (1) an intuitive interface for validated data capture, (2) trail audits for tracking data manipulation and export procedures, (3) automated export procedures for seamless data downloads to common statistical packages, and (4) procedures for data integration and interoperability with external sources.

In 2020, the Core Registry collected data in the following areas:

1. Names, sites, and specific facility of the entering medical toxicologist(s)

2. Specific focused data collections on areas of contemporary interest

3. Medication errors and adverse reactions associated with therapeutic use

4. Patient demographics

5. HIV status

6. Specific aspects of the patient's medical history

7. The source of the patient referral

8. The reasons for the patient requiring a medical toxicology consultation

9. The implicated substance(s) and their relationship, if any, to the patient's presentation

10. Patient signs and symptoms

11. Specific laboratory and electrocardiographic data

12. Treatments administered

13. Outcome

ToxIC's data collection in 2020 included the addition of teletoxicology and COVID-19 status (defined as a positive SARS-CoV-2 test). A full enumeration of all fields collected in the Core Registry is provided in the supplemental materials.

In addition to the Core Registry data collected on every bedside medical toxicology consultation, there are five detailed Sub-Registries that are completed on relevant patients. These are:

1. North American Snakebite Registry

2. Pediatric Marijuana and Opioid Registry

3. Extracorporeal Therapies Registry

4. Lipid Emulsion Therapy Registry

5. Natural Toxins Registry: Mushrooms and Plants

ToxIC has been reviewed by the Western Institutional Review Board (IRB) and operates in pursuant to the approval of the participating site IRBs. All data collected by ToxIC is deidentified and is compliant with the Health Insurance Portability and Accountability Act. All cases entered into the Core Registry, Sub-Registries, FACT Pharmacovigilance Project, and the Fentalog project are reviewed for quality assurance by the ToxIC staff. Any inconsistent or incomplete entries are queried back to the entering medical toxicologist for correction or clarification.

Additional information regarding ToxIC can be found at https://www.toxicregistry.org.

\section{Results}

In 2020 there were a total of 6668 individual cases of toxicologic exposures reported to the ToxIC Registry from 37 sites comprised of 58 separate health care facilities. This is a decrease in total cases compared with 2019 [2]. Individual facilities contributing cases in 2020 are listed in Table 1.

\section{Demographics}

Tables 2 and 3 summarize selective demographics for age and gender and race and ethnicity, respectively. Gender breakdown was similar to recent years [2-5]. In 2020, 50.6\% of cases involved female patients, and $1 \%$ involved transgender or gender non-conforming patients (37 female-to-male, 17 male-to-female, 8 gender non-conforming). Sixty-nine patients $(1 \%)$ were pregnant. Age distribution was similar to recent years. Adults age 19-65 made up approximately half of the cases $(55.5 \%)$ followed by adolescents age 13-18 (24.6\%). Children ( $\leq 12$ years of age) made up $9.5 \% ; 5.9 \%$ of cases involved older adults ( $>65$ years of age).

The most commonly reported race was Caucasian $(62.6 \%)$, followed by Black/African (15.1\%) and Asian (2.3\%). Hispanic ethnicity was reported in $12.4 \%$ of cases; however $15.7 \%$ of cases reported ethnicity as unknown/uncertain. Race and ethnicity are self-reported by patients, or in cases in which a patient is unable to report, it may be determined by the examining medical toxicologist to the best of their ability or abstracted from the medical record.

Table 4 details the referral source of inpatient and outpatient medical toxicology encounters. The majority $(53.5 \%)$ of inpatient cases were generated by the emergency department, and very few cases were referred from poison centers $(0.2 \%)$ or outpatient physicians $(0.2 \%)$. Outpatient encounters were primarily referred by primary care and other outpatient physicians $(68.7 \%)$, followed by self-referrals $(11.0 \%)$. These trends were similar to recent years.

Tables 5 and 6 describe the reason for the toxicology encounter and the details of intentional pharmaceutical exposures, respectively. Consistent with recent years, intentional pharmaceutical exposures were by far the most common reason for medical toxicology encounters (43.8\%). Addiction medicine consult was a new reason for encounter in 2018 and has increased in frequency each year $(2.7 \%$ to $6.6 \%$ to $7.1 \%$ ) $[2,3]$. Within the intentional pharmaceutical exposures, 


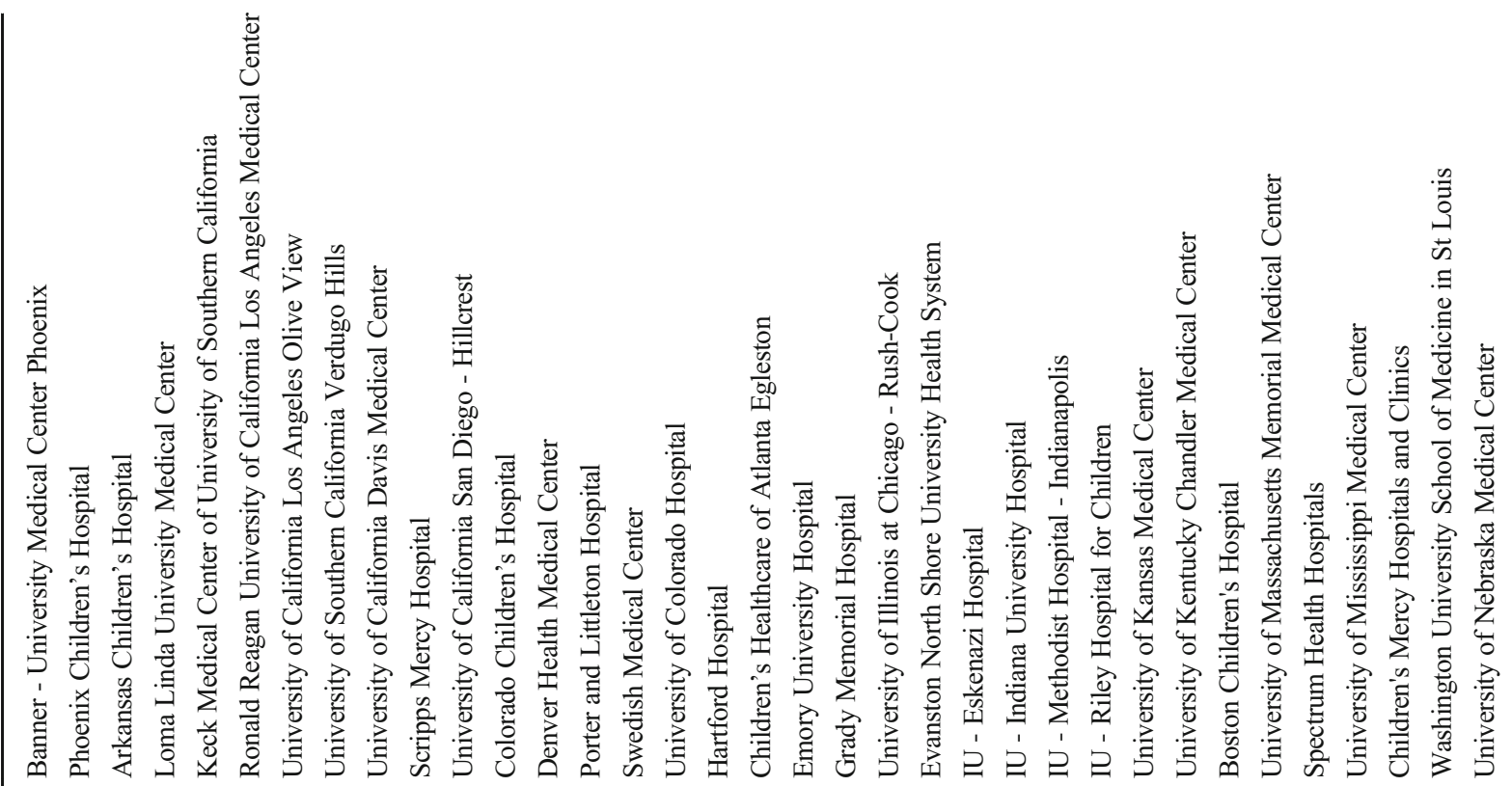

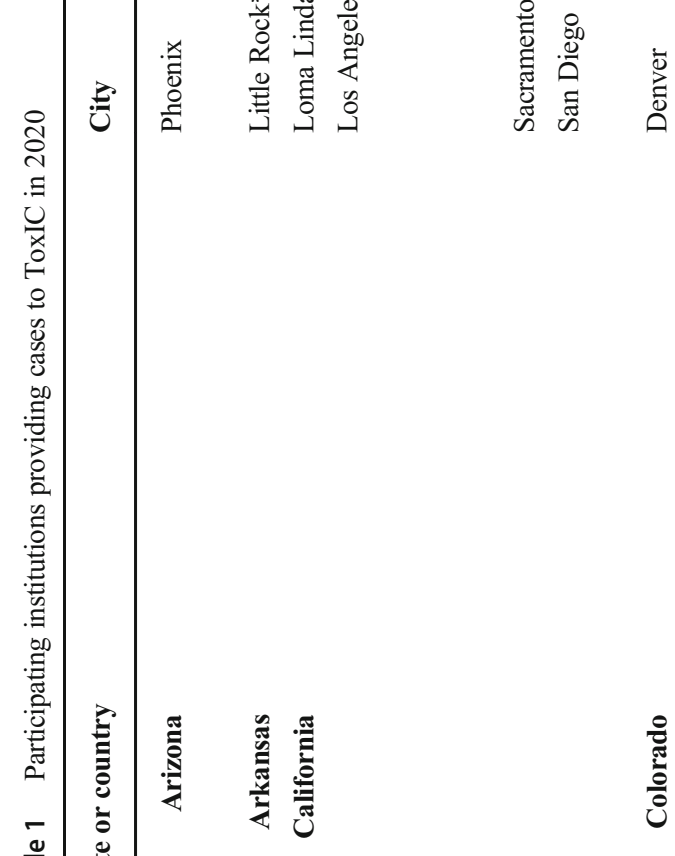
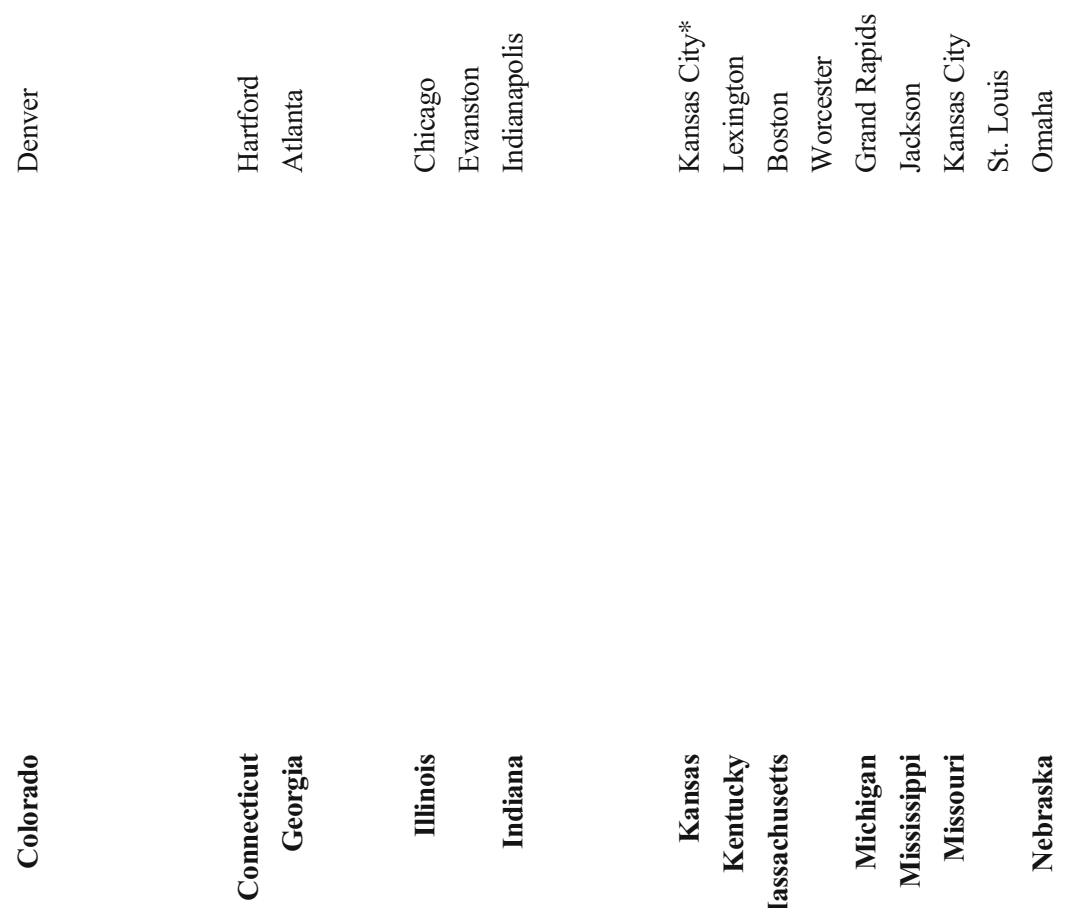

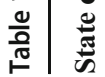




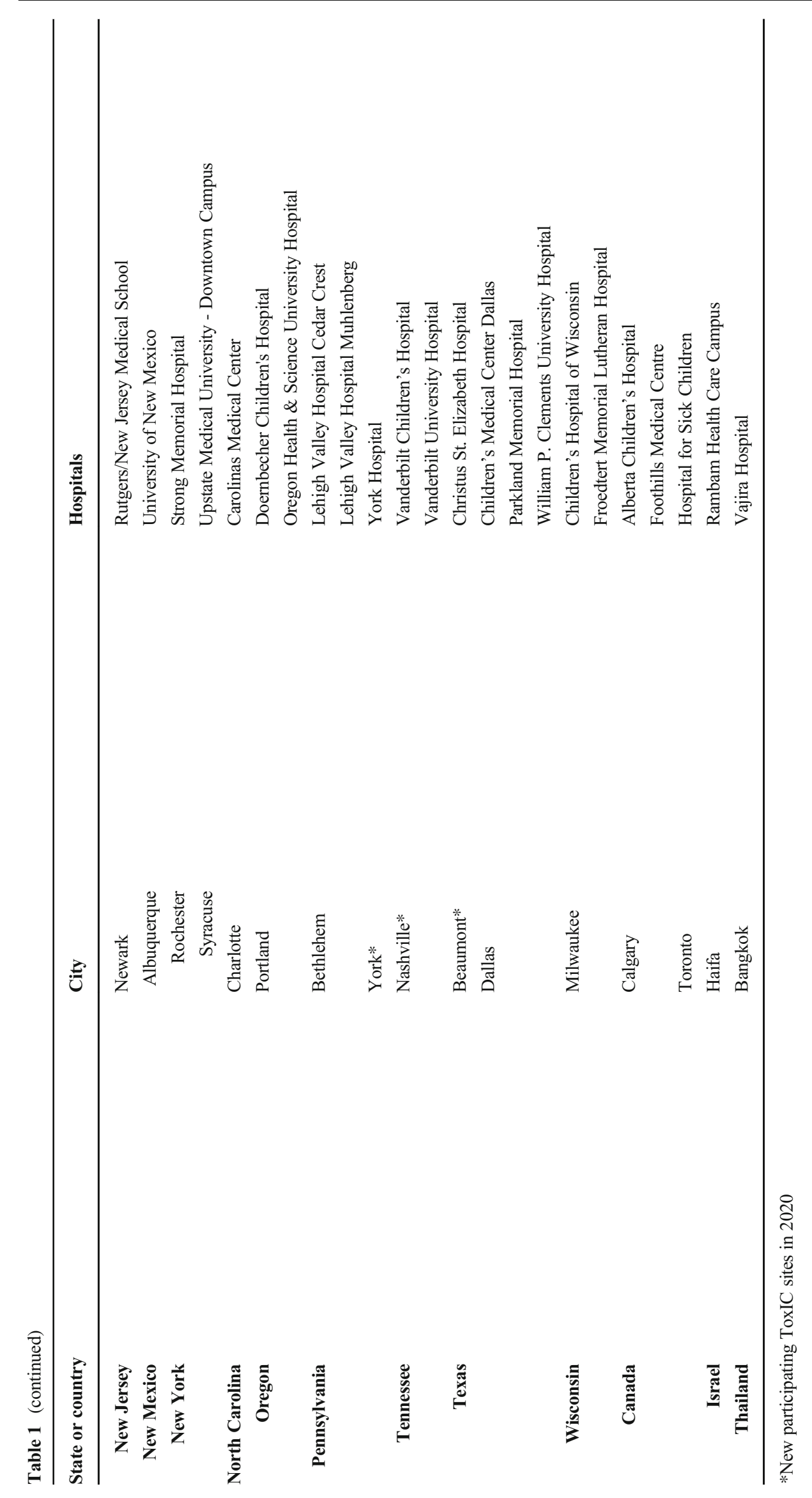


Table 2 ToxIC case demographics - gender and age

\begin{tabular}{|c|c|c|}
\hline & & $\mathrm{N}(\%)$ \\
\hline Male & & $3227(48.4)$ \\
\hline Female & & $3377(50.6)$ \\
\hline \multirow[t]{4}{*}{ Transgender } & & $64(0.96)$ \\
\hline & Male to female & $17(26.6)$ \\
\hline & Female to male & $37(57.8)$ \\
\hline & Gender non-conforming & $8(12.5)$ \\
\hline Total & & 6668 \\
\hline Pregnant & & $69(1.0)$ \\
\hline \multicolumn{3}{|l|}{ Age (years) } \\
\hline$<2$ & & $250(3.7)$ \\
\hline $2-6$ & & $386(5.8)$ \\
\hline $7-12$ & & $275(4.1)$ \\
\hline $13-18$ & & $1639(24.6)$ \\
\hline $19-65$ & & $3704(55.5)$ \\
\hline $66-89$ & & $376(5.6)$ \\
\hline$>89$ & & $10(0.1)$ \\
\hline Unknown & & $28(0.4)$ \\
\hline Total & & $6668(100)$ \\
\hline
\end{tabular}

the majority of cases were again an attempt at self-harm $(73.9 \%)$, primarily suicide attempts $(87.5 \%)$.

Tables 7 and 8 describe the top three primary reasons for encounter by race and ethnicity, respectively. Distribution of reasons for encounter was largely similar across races and ethnicities, with intentional pharmaceutical exposures being

Table 3 ToxIC case demographics — race and Hispanic ethnicity

\begin{tabular}{ll}
\hline & $N(\%)$ \\
\hline Race & \\
Caucasian & $4174(62.6)$ \\
Black/African & $1007(15.1)$ \\
Asian & $245(2.3)$ \\
American Indian/Alaska Native & $73(1.1)$ \\
Native Hawaiian or Pacific Islander & $7(0.1)$ \\
Mixed & $109(1.6)$ \\
Other & $13(0.2)$ \\
Unknown & $1129(16.9)$ \\
Missing & $1(0.01)$ \\
Total & 6668 \\
Hispanic Ethnicity & \\
Hispanic & $828(12.4)$ \\
Non-Hispanic & $4793(71.9)$ \\
Unknown & $1047(15.7)$ \\
Total & 6668 \\
\hline
\end{tabular}

${ }^{a}$ Hispanic ethnicity as indicated exclusive of race the most common reason for encounter across all groups. Of note, however snake envenomation was a top three encounter reason among Native American/Alaska Native (8.2\%) and Asian (17.4\%) race groups, but not among other race groups. Addiction medicine consultation was the primary reason for the encounter in $5.9 \%$ of non-Hispanic patients, but only $3.4 \%$ of Hispanic patients.

\section{Agent classes}

Agent class contributions to the Core Registry are described in Table 9. In 2020, of the 6668 cases entered into the ToxIC Registry, 5987 included specific agents of exposure. Four thousand two hundred sixty-two (71.2\%) cases involved single agents. Consistent with recent years, the non-opioid analgesic class was the most common (15.5\%) class of drugs reported. Again in 2020, the opioid class was the second most common agent class reported (12.7\%) [2] followed by the antidepressant (10.4\%) and ethanol (8.4\%) classes.

Tables 10 and 11 detail the top five agent classes broken down by race and ethnicity, respectively. The primary substance responsible for most encounters varied across racial groups: ethanol for Native Americans/Alaska Natives (13.7\%); analgesics for Asians (10.3\%), Caucasians (14.4\%), and mixed-race patients $(21.1 \%)$; opioids for Blacks (17.0\%); and toxic alcohols for Pacific Islanders/ Native Hawaiians (28.6\%). Primary substances associated with both Hispanic and non-Hispanic patient encounters were similar.

\section{Analgesics}

Table 12 presents the non-opioid analgesics, the largest class in the Core Registry. Acetaminophen was again the most commonly reported agent (64.6\%), reaching its claim as the highest reported drug of exposure every year since ToxIC was established. It is distantly followed by ibuprofen (12.3\%), aspirin $(6.7 \%)$, and gabapentin $(6.5 \%)$. Aspirin and acetylsalicylic acid are listed separately in the registry; when combined they compose $11.0 \%$ of the non-opioid analgesic class.

\section{Opioids}

Table 13 describes the opioid class. Similar to recent years, heroin was again the most common agent in the class (32.1\%) $[2,3]$. The relative contribution of fentanyl increased again this year, now representing $25.4 \%$ of the opioid class (14.6\% in 2019), and again was the second most common agent.[2] Oxycodone was the third most common agent reported again this year (13.9\%) [2]. Other opioid agents remained fairly stable compared with prior years. 
Table 4 ToxIC registry case referral sources by inpatient/ outpatient status
$N(\%)$

Emergency department (ED) or inpatient (IP) ${ }^{a}$

ED

Admitting service

$2199(33.8)$

Request from another hospital service (not ED)

$412(6.3)$

Outside hospital transfer

Poison center

Primary care provider or other outpatient treating physician

Employer/independent medical evaluation

Self-referral

$\mathrm{ED} / \mathrm{IP}$ total

Outpatient (OP)/clinic/office consultation ${ }^{b}$

Primary care provider or other OP physician

Self-referral

Employer/independent medical evaluation

Poison center

Request from another hospital service (not ED)

Admitting service

$0(0.0)$

Outside hospital transfer

$163(100)$

${ }^{a}$ Percentage based on the total number of cases $(N=6505)$ seen by a medical toxicologist as consultant (ED or IP) or as attending (IP)

${ }^{b}$ Percentage based on the total number of cases $(\mathrm{N}=163)$ seen by a medical toxicologist as outpatient, clinic visit, or office consultation.

Table 14 describes breakdown of analgesics by race. In comparing opioid and non-opioid analgesic agents, acetaminophen was associated with the highest percentage of encounters across most racial sub-groups. However, among
Table 5 Reason for medical toxicology encounter

\begin{tabular}{ll}
\hline & $N(\%)$ \\
\hline Intentional exposure-pharmaceutical & $3288(43.8)$ \\
Intentional exposure - non-pharmaceutical & $935(12.5)$ \\
Unintentional exposure - pharmaceutical & $546(7.3)$ \\
Addiction medicine consultation & $532(7.1)$ \\
Withdrawal—-thanol & $399(5.3)$ \\
Unintentional exposure-non-pharmaceutical & $336(4.5)$ \\
Organ system dysfunction & $269(3.6)$ \\
Envenomation-snake & $263(3.5)$ \\
Ethanol abuse & $242(3.2)$ \\
Withdrawal—opioid & $234(3.1)$ \\
Interpretation of toxicology lab data & $164(2.2)$ \\
Environmental evaluation & $89(1.2)$ \\
Withdrawal—sedative/hypnotic & $51(0.7)$ \\
Occupational evaluation & $49(0.7)$ \\
Envenomation-spider & $25(0.3)$ \\
Withdrawal—other & $19(0.3)$ \\
Envenomation-other & $19(0.3)$ \\
Malicious/criminal & $19(0.3)$ \\
Withdrawal—cocaine/amphetamine & $10(0.1)$ \\
Envenomation-scorpion & $7(0.1)$ \\
Marine /fish poisoning & $5(0.1)$ \\
Total & $7501(100)$ \\
\hline
\end{tabular}

Table 6 Detailed reason for encounter-intentional pharmaceutical exposure $^{\mathrm{a}}$

\begin{tabular}{lc}
\hline & $N(\%)^{a}$ \\
\hline Reason for intentional pharmaceutical exposure subgroup ${ }^{b}$ \\
Attempt at self-harm & $2408(73.9)$ \\
Misuse/abuse & $404(12.4)$ \\
Therapeutic use & $240(7.4)$ \\
Unknown & $207(6.4)$ \\
Total & $3259(100)$ \\
Attempt at self-harm- suicidal intent subclassification & \\
Suicidal intent & $2105(87.5)$ \\
Suicidal intent unknown & $217(9.0)$ \\
No suicidal intent & $84(3.5)$ \\
Total & $2406(100)$ \\
\hline
\end{tabular}

${ }^{a}$ Nine cases listed more than one reason for encounter due to intentional pharmaceutical exposure $(N=3251)$

${ }^{b}$ Percentage of total number indicating reason for encounter due to intentional pharmaceutical exposure

${ }^{c}$ Percentage of number of cases indicating attempt at self-harm 
Table 7 Top three primary reasons for encounter by race

\begin{tabular}{ll}
\hline & $N(\%)$ \\
\hline Native American/Alaska Native & $\mathbf{7 3 ( 1 . 1 )}$ \\
Intentional pharmaceutical & $31(42.3)^{b}$ \\
Intentional non-pharmaceutical & $11(15.1)$ \\
Envenomation snake & $6(8.2 \%)$ \\
Unintentional pharmaceutical & $6(8.2 \%)$ \\
Asian & $\mathbf{1 5 5}(\mathbf{2 . 3})$ \\
Intentional pharmaceutical & $68(43.9)$ \\
Envenomation snake & $27(17.4)$ \\
Unintentional pharmaceutical & $13(8.4)$ \\
Black & $\mathbf{1 0 0 7}(\mathbf{1 5 . 1})$ \\
Intentional pharmaceutical & $458(45.5)$ \\
Intentional non-pharmaceutical & $144(14.3)$ \\
Unintentional pharmaceutical & $119(11.8)$ \\
Caucasian & $\mathbf{4 1 7 4 ( 6 2 . 6 )}$ \\
Intentional pharmaceutical & $1987(47.6)$ \\
Intentional non-pharmaceutical & $542(13)$ \\
Unintentional pharmaceutical & $287(6.9)$ \\
Pacific Islander/Native Hawaiian & $\mathbf{7 ( 0 . 1 )}$ \\
Intentional pharmaceutical & $3(42.9)$ \\
Unintentional non-pharmaceutical & $2(28.6)$ \\
Intentional non-pharmaceutical & $1(14.3)$ \\
Organ system dysfunction & $1(14.3)$ \\
Mixed race & $\mathbf{1 0 9}(\mathbf{1 . 6})$ \\
Intentional pharmaceutical & $60(55.0)$ \\
Intentional non-pharmaceutical & $19(17.4)$ \\
Unintentional pharmaceutical & $13(11.9)$ \\
\hline
\end{tabular}

${ }^{a}$ Percentages in bold based on the number of cases in a given race category in 2020 relative to the total number of Core Registry cases in 2020 $(N=6668)$

${ }^{b}$ Percentages based on number of cases for a primary encounter type relative to the number of cases in given race category in 2020

Black and Caucasian patients, opioids were associated with more encounters compared with other individual non-opioid analgesics $(17.0 \%$ Black patients and $12.7 \%$ Caucasian patients).

\section{Antidepressants}

Table 15 describes the antidepressant class. SSRIs (39.5\%) and other antidepressants $(37.4 \%)$ represented the majority of this class. Sertraline (14.5\%) was the most common SSRI reported and bupropion (21.6\%) was the most common other antidepressant, similar to last year.[2]

\section{Sedative hypnotics}

Table 16 presents the sedative hypnotic/muscle relaxant class. Benzodiazepines (primarily alprazolam (25.8\%) and
Table 8 Top three primary reasons for encounter by ethnicity

\begin{tabular}{|c|c|}
\hline & $\mathrm{N}(\%)$ \\
\hline Hispanic patients & $828(12.4)^{a}$ \\
\hline Intentional pharmaceutical & $406(49.0)^{b}$ \\
\hline Intentional non-pharmaceutical & $121(14.6)$ \\
\hline Unintentional non-pharmaceutical & $63(7.6)$ \\
\hline Non-Hispanic patients & 4793 (71.9) \\
\hline Intentional pharmaceutical & $2237(46.7)$ \\
\hline Intentional non-pharmaceutical & $614(12.8)$ \\
\hline Unintentional pharmaceutical & $390(8.1)$ \\
\hline
\end{tabular}

${ }^{a}$ Percentages in bold based on the number of cases in a given ethnicity category in 2020 relative to the total number of Core Registry cases in $2020(N=6668)$

${ }^{b}$ Percentages based on number of cases for a primary encounter type relative to the number of cases in given ethnicity category in 2020

clonazepam (12.2\%)) and muscle relaxants (primarily baclofen $(10.2 \%)$ and cyclobenzaprine $(7.9 \%)$ ) were the most common subtypes, similar to recent years. Other sedatives, Zdrugs, and barbiturates were again less common.

\section{Toxic alcohol and ethanol}

Table 17 describes data on ethanol and toxic alcohols. Ethanol was considered its own agent class, consistent with prior years and was the fourth most commonly reported agent class (up from fifth in 2019) [2]. The most commonly reported nonethanol alcohols and glycols were ethylene glycol $(47.0 \%)$ and isopropanol (31.8\%). Methanol and miscellaneous alcohols each made up $10.6 \%$ of the class.

\section{Sympathomimetics}

Table 18 presents the sympathomimetic class. This year, methamphetamine $(40.3 \%)$ overtook cocaine $(23.9 \%)$ as the most common agent in this class, followed again by amphetamine (10.1\%).

\section{Anticholinergic/antihistamine}

Table 19 describes the anticholinergic/antihistamine class. Consistent with recent years, diphenhydramine $(58.6 \%)$, followed by hydroxyzine ( $18.1 \%)$, remains the most commonly reported agents in this class.

\section{Cardiovascular agents}

Table 20 shows data on the cardiovascular class. Consistent with recent years, sympatholytics $(32.5 \%)$ remain the most common subclass of cardiovascular drugs, followed by betablockers $(23.5 \%)$ and calcium channel blockers $(16.5 \%)$. 
Table 9 Agent classes involved in medical toxicology consultation

\begin{tabular}{|c|c|}
\hline & $N(\%)^{a}$ \\
\hline Analgesic & $1377(15.5)$ \\
\hline Opioid & $1128(12.7)$ \\
\hline Antidepressant & $923(10.4)$ \\
\hline Ethanol & $743(8.4)$ \\
\hline Sedative-hypnotic/muscle relaxant & $599(6.8)$ \\
\hline Sympathomimetic & $566(6.4)$ \\
\hline Cardiovascular & $520(5.9)$ \\
\hline Anticholinergic/antihistamine & $514(5.8)$ \\
\hline Antipsychotic & $409(4.6)$ \\
\hline Psychoactive & $306(3.5)$ \\
\hline Anticonvulsant & $252(2.8)$ \\
\hline Envenomation and marine & $250(2.8)$ \\
\hline Diabetic medication & $129(1.5)$ \\
\hline Lithium & $105(1.2)$ \\
\hline Cough and cold products & $89(1.0)$ \\
\hline Herbal products/dietary supplements & $89(1.0)$ \\
\hline Unknown class & $87(1.0)$ \\
\hline Metals & $86(1.0)$ \\
\hline Household products & $71(0.8)$ \\
\hline Gases/irritants/vapors/dusts & $69(0.8)$ \\
\hline Caustic & $67(0.8)$ \\
\hline Toxic alcohols & $67(0.8)$ \\
\hline Antimicrobials & $63(0.7)$ \\
\hline Plants and fungi & $49(0.6)$ \\
\hline Hydrocarbon & $41(0.5)$ \\
\hline GI & $39(0.4)$ \\
\hline Chemotherapeutic and immune & $30(0.3)$ \\
\hline Anticoagulant & $25(0.3)$ \\
\hline Other pharmaceutical product & $25(0.3)$ \\
\hline Endocrine & $24(0.3)$ \\
\hline Anesthetic & $24(0.3)$ \\
\hline Other nonpharmaceutical product & $23(0.3)$ \\
\hline Herbicide & $11(0.1)$ \\
\hline Insecticide & $11(0.1)$ \\
\hline Rodenticide & $9(0.1)$ \\
\hline Pulmonary & $9(0.1)$ \\
\hline Ingested foreign body & $7(0.1)$ \\
\hline Amphetamine-like hallucinogen & $7(0.1)$ \\
\hline WMD/riot agent/radiological & $5(0.1)$ \\
\hline Anti-parkinsonism drugs & $5(0.1)$ \\
\hline Marine toxin & $3(0.0)$ \\
\hline Cholinergic & $1(0.0)$ \\
\hline Class total & $8857(100)$ \\
\hline
\end{tabular}

${ }^{a}$ Percentages are out of total number of reported agent entries in 2020 from 5987 unique cases; 4262 cases $(71.2 \%)$ reported single agents

WMD weapons of mass destruction

Clonidine (24.0\%) and metoprolol (10.0\%) were again the most common sympatholytic and beta-blocker agents,
Table 10 Top five primary agent classes by race ${ }^{a}$

\begin{tabular}{ll}
\hline Native American/Alaska Native & $N(\%)$ \\
Ethanol & $\mathbf{7 3 ( 1 . 1 ) ^ { b }}$ \\
Analgesic & $10(13.7)^{c}$ \\
Envenomation & $9(12.3)$ \\
Alcohol-toxic & $5(6.8)$ \\
Anticonvulsant & $4(5.5)$ \\
Opioid & $4(5.5)$ \\
Asian & $4(5.5)$ \\
Analgesic & $\mathbf{1 5 5}(\mathbf{2 . 3})$ \\
Antidepressant & $16(10.3)$ \\
Ethanol & $9(5.8)$ \\
Cardiovascular & $6(3.9)$ \\
Envenomation & $6(3.9)$ \\
\end{tabular}

Black

1007 (15.1)

Opioids

$171(17.0)$

Analgesic

$163(16.2)$

Cardiovascular $\quad 71(7.1)$

Antidepressant $58(5.8)$

Antipsychotics $\quad 50(5.0)$

Caucasian

4174 (62.6)

Analgesic

$602(14.4)$

Opioids

$530(12.7)$

Ethanol

$431(10.3)$

Antidepressant $350(8.4)$

Sympathomimetic $214(5.1)$

Pacific Islander/Native Hawaiian 7 (0.1)

Toxic Alcohol 2 (28.6)

Analgesic $1(14.3)$

Anticoagulant $1(14.3)$

Antipsychotic $1(14.3)$

Opioid $1(14.3)$

Psychoactive $1(14.3)$

Mixed Race $109(1.6)$

Analgesic $23(21.1)$

Sympathomimetic 15 (13.8)

Opioids $11(10.1)$

Cardiovascular $\quad 8$ (7.3)

Antidepressant 7 (6.4)

Psychoactive 7 (6.4)

${ }^{a}$ Counts include only the primary agent \#1 selected for each Core Registry case

${ }^{b}$ Percentages in bold based on the number of cases in a given race category in 2020 relative to the total number of Core Registry cases in 2020 $(N=6668)$

${ }^{c}$ Percentages based on number of cases for an agent type relative to the number of cases in given race category in 2020

respectively. Amlodipine (9.8\%) remained the most common calcium channel blocker. 
Table 11 Top five primary agent classes by ethnicity $^{a}$

\begin{tabular}{|c|c|}
\hline & $N(\%)$ \\
\hline Hispanic patients & $828(12.4)^{b}$ \\
\hline Analgesic & $155(18.7)^{c}$ \\
\hline Opioids & $115(13.9)$ \\
\hline Antidepressant & $52(6.3)$ \\
\hline Ethanol & $46(5.6)$ \\
\hline Sympathomimetic & $46(5.6)$ \\
\hline Non-Hispanic Patients & 4793 (71.9) \\
\hline Analgesic & $672(14.0)$ \\
\hline Opioids & $627(13.1)$ \\
\hline Ethanol & $454(9.5)$ \\
\hline Antidepressant & $375(7.8)$ \\
\hline Sympathomimetic & $255(5.3)$ \\
\hline \multicolumn{2}{|c|}{$\begin{array}{l}{ }^{a} \text { Counts include only the primary agent \#1 } \\
\text { selected for each Core Registry case }\end{array}$} \\
\hline \multicolumn{2}{|c|}{$\begin{array}{l}{ }^{b} \text { Percentages in bold based on the number } \\
\text { of cases in a given ethnicity category in } \\
2020 \text { relative to the total number of Core } \\
\text { Registry cases in } 2020(N=6668)\end{array}$} \\
\hline \multicolumn{2}{|c|}{$\begin{array}{l}{ }^{c} \text { Percentages based on number of cases for } \\
\text { an agent type relative to the number of } \\
\text { cases in given ethnicity category in } 2020\end{array}$} \\
\hline
\end{tabular}

\section{Antipsychotics}

Table 21 details the antipsychotic class. Trends in the antipsychotic class were similar to recent years. The atypicals, led by quetiapine (41.3\%) and olanzapine (13.2\%), represent the majority of cases reported.

Table 12 Analgesics

\begin{tabular}{ll}
\hline & $N(\%)$ \\
\hline Acetaminophen & $890(64)$ \\
Ibuprofen & $169(12)$ \\
Aspirin & $92(6.7)$ \\
Gabapentin & $90(6.5)$ \\
Acetylsalicylic acid & $59(4.3)$ \\
Naproxen & $41(3.0)$ \\
Pregabalin & $14(1.0)$ \\
Salicylic acid & $6(0.4)$ \\
Meloxicam & $5(0.4)$ \\
Miscellaneous & $11(0.8)$ \\
Class total $^{\mathrm{a}}$ & $\mathbf{1 3 7 7}(\mathbf{1 0 0})$ \\
\hline
\end{tabular}

ancludes analgesic unspecified, diclofenac, indomethacin, ketorolac, metamizole (dipyrone), nabumetone, phenazopyridine, salsalate, ziconotide
Table 13 Opioids

\begin{tabular}{ll}
\hline & $N(\%)$ \\
\hline Heroin & $362(32.1)$ \\
Fentanyl & $286(25.4)$ \\
Oxycodone & $157(13.9)$ \\
Buprenorphine & $72(6.4)$ \\
Methadone & $49(4.3)$ \\
Tramadol & $45(4.0)$ \\
Opioid Unspecified & $37(3.3)$ \\
Hydrocodone & $34(3.0)$ \\
Morphine & $30(2.7)$ \\
Hydromorphone & $16(1.4)$ \\
Codeine & $14(1.2)$ \\
Naloxone & $14(1.2)$ \\
Miscellaneous & $a$ \\
Class total & $12(1.1)$ \\
\hline
\end{tabular}

${ }^{a}$ Includes bucinnazine (AP 237, 1-butyryl4-cinnamylpiperazine), loperamide, naltrexone, tapentadol

\section{Anticonvulsants, mood stabilizers, and lithium}

Table 22 presents data on anticonvulsants, mood stabilizers, and lithium. Consistent with past years, lithium was considered as its own agent class and made up just over $1 \%$ of reported agents in the Core Registry [2, 3]. Among anticonvulsants and mood stabilizers, lamotrigine (29.4\%) and valproic acid (19.4\%) were the most commonly reported agents followed by oxcarbazepine $(10.7 \%)$ and phenytoin $(9.5 \%)$

\section{Psychoactives}

Table 23 presents data on the psychoactive class including the

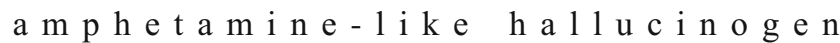
methylenedioxymethamphetamine (Molly). Marijuana was again the most common agent in this class $(25.5 \%)$ followed closely by tetrahydrocannabinol $(20.3 \%)$. Synthetic cannabinoid cases continued to fall again this year $(5.6 \%$ in $2020 \mathrm{vs}$ $9.4 \%$ in 2019 and $12.3 \%$ in 2018) [2-4]. When combined, all non-synthetic cannabinoid product exposures represented $65.7 \%$ of the psychoactive class. Molly exposures remained low, with 7 cases reported.

\section{Envenomations and marine poisonings}

Table 24 shows data on envenomations and marine poisonings. Snake envenomations represented by Crotalus (35.6\%), Agkistrodon (34.4\%), and snake unspecified (17.0) were the top three exposures reported to this class. Agkistrodon envenomations showed an increase this year from $16.9 \%$ in 
Table 14 Comparison of opioid and non-opioid analgesic frequencies by race ${ }^{a}$

\begin{tabular}{ll}
\hline & $N(\%)$ \\
\hline Native American/Alaska Native & $\mathbf{7 3 ( 1 . 1 )}$ \\
Acetaminophen & $7(9.6)^{c}$ \\
Opioid & $4(5.5)$ \\
Salicylates & $1(1.4)$ \\
Ibuprofen & $1(1.4)$ \\
Asian & $\mathbf{1 5 5}(\mathbf{2 . 3 )}$ \\
Acetaminophen & $12(7.7)$ \\
Opioid & $4(2.6)$ \\
Salicylates & $2(1.3)$ \\
Ibuprofen & $2(1.3)$ \\
Black & $\mathbf{1 0 0 7}(\mathbf{1 5 . 1})$ \\
Opioids & $171(17.0)$ \\
Acetaminophen & $129(12.8)$ \\
Salicylates & $14(1.4)$ \\
NSAIDs & $12(1.2)$ \\
Gabapentin/Pregabalin & $8(0.8)$ \\
Caucasian & $\mathbf{4 1 7 4 ( 6 2 . 6 )}$ \\
Opioids & $530(12.7)$ \\
Acetaminophen & $451(10.8)$ \\
Salicylates & $71(1.7)$ \\
NSAIDs & $56(1,3)$ \\
Gabapentin/Pregabalin & $22(0.5)$ \\
Pacific Islander/Native Hawaiian & $\mathbf{7 ( 0 . 1 )}$ \\
Acetaminophen & $1(14.2)$ \\
Opioid & $1(14.2)$ \\
Mixed Race & $\mathbf{1 0 9}(\mathbf{1 . 6})$ \\
Acetaminophen & $17(15.6)$ \\
Opioids & $11(10.1)$ \\
Salicylates & $5(4.6)$ \\
\hline buprofen & $1(0.9)$ \\
\hline
\end{tabular}

${ }^{a}$ Counts include only cases for which an opioid or non-opioid analgesic was selected as primary agent \#1

${ }^{b}$ Percentages in bold based on the number of cases in a given race category in 2020 relative to the total number of Core Registry cases in 2020 $(N=6668)$

${ }^{c}$ Percentages based on number of cases for an agent type relative to the number of cases in given race category in 2020

2019, nearly approaching that of Crotalus envenomations. Again in 2020, Loxosceles exposures were the fourth most common exposure in this class $(5.1 \%)[2-4]$.

\section{Diabetic agents}

Table 25 presents the diabetic medication agent class. Metformin was the most common agent at $39.4 \%$ of the agent class, followed by insulin $(22.5 \%)$ and glipizide $(21.7 \%)$.
Table 15 Antidepressants

\begin{tabular}{ll}
\hline & $N(\%)$ \\
\hline Selective serotonin reuptake inhibitors (SSRIs) & $\mathbf{3 6 5}(\mathbf{3 9 . 5})$ \\
Sertraline & $134(14.5)$ \\
Escitalopram & $87(9.4)$ \\
Fluoxetine & $86(9.3)$ \\
Citalopram & $45(4.9)$ \\
Paroxetine & $10(1.1)$ \\
Vilazodone & $3(0.3)$ \\
Other antidepressants & $\mathbf{3 4 5}(\mathbf{3 7 . 4 )}$ \\
Bupropion & $199(21.6)$ \\
Trazodone & $118(12.8)$ \\
Mirtazapine & $20(2.2)$ \\
Miscellaneous & \\
Antidepressant unspecified & $5(0.5)$ \\
Tricyclic antidepressants (TCAs) & $3(0.3)$ \\
Amitriptyline & $\mathbf{9 5}(\mathbf{1 0 . 3})$ \\
Doxepin & $66(7.2)$ \\
Nortriptyline & $11(1.2)$ \\
Miscellaneous ${ }^{\mathrm{b}}$ & $9(1.0)$ \\
Serotonin-norepinephrine reuptake inhibitors (SNRIs) & $9(1.0)$ \\
Venlafaxine & $\mathbf{1 1 6}(\mathbf{1 2 . 6})$ \\
Duloxetine & $67(7.3)$ \\
Miscellaneous ${ }^{\mathrm{c}}$ & $44(4.8)$ \\
Monoamine oxidase inhibitor (MAOIs) & $5(0.5)$ \\
Phenelzine & $\mathbf{2 ( 0 . 2 )}$ \\
Class total & $2(0.2)$ \\
\hline${ }^{a}$ Includes vortioxetine, tianeptine, sibutramine & $923(100)$ \\
${ }^{b}$ Includes imipramine, clomipramine, desipramine, noxiptiline \\
${ }^{c}$ Includes desvenlafaxine, levomilnacipran \\
\end{tabular}

Table 26 presents the metal class. Lithium is its own agent class and is reported with the anticonvulsants and mood stabilizers. Trends were similar to recent years with lead (37.6\%) and iron (28.2\%) composing the majority of reported cases [2-4]. Mercury and arsenic were reported each in $6(7.1 \%)$ cases.

\section{Herbal products and dietary supplements}

Table 27 details herbal products and dietary supplements. Caffeine (38.2\%) and melatonin again made up the majority of this class $[2,3]$. Infrequently reported miscellaneous agents made up $38.2 \%$ of the agent class.

\section{Household agents}

Table 28 describes household agents reported to the Core Registry. Cleaning solutions and disinfectants (28.2\%), 
Table 16 Sedative-hypnotic/muscle relaxants by type

\begin{tabular}{|c|c|}
\hline & $N(\%)$ \\
\hline Benzodiazepine & 357 (59.7) \\
\hline Alprazolam & $154(25.8)$ \\
\hline Clonazepam & $73(12.2)$ \\
\hline Lorazepam & $54(9.0)$ \\
\hline Benzodiazepine unspecified & $32(5.4)$ \\
\hline Diazepam & $26(4.3)$ \\
\hline Temazepam & $8(1.3)$ \\
\hline Midazolam & $5(0.8)$ \\
\hline Miscellaneous $^{a}$ & $5(0.8)$ \\
\hline Muscle relaxant & $156(26.1)$ \\
\hline Baclofen & $61(10.2)$ \\
\hline Cyclobenzaprine & $47(7.9)$ \\
\hline Tizanidine & $35(5.9)$ \\
\hline Methocarbamol & $5(0.8)$ \\
\hline Carisoprodol & $5(0.8)$ \\
\hline Metaxalone & $3(0.5)$ \\
\hline Other sedatives & $35(5.9)$ \\
\hline Buspirone & $16(2.7)$ \\
\hline Sed-hypnotic/muscle relaxant unspecified & $10(1.7)$ \\
\hline Miscellaneous $^{b}$ & $9(1.5)$ \\
\hline Non-benzodiazepine agonists ("Z" drugs) & $34(5.7)$ \\
\hline Zolpidem & $33(5.5)$ \\
\hline Eszopiclone & $1(0.2)$ \\
\hline Barbiturates & $15(2.5)$ \\
\hline Phenobarbital & $5(0.8)$ \\
\hline Butalbital & $5(0.8)$ \\
\hline Miscellaneous $^{c}$ & $5(0.8)$ \\
\hline Paralytic & $1(0.2)$ \\
\hline Vecuronium & $1(0.2)$ \\
\hline Class total & $598(100)$ \\
\hline
\end{tabular}

${ }^{a}$ Includes chlordiazepoxide and bromazepam

${ }^{b}$ Includes propofol, phenibut (beta-phenyl-gamma-aminobutyric acid), meprobamate, flumazenil, etizolam, and acamprosate

${ }^{c}$ Includes butabarbital, pentobarbital, and barbituate unspecified

laundry detergent pods (19.7\%), and sodium hypochlorite $\leq 6 \%$ $(12.7 \%)$ were the most commonly reported agents in this class.

\section{Gases, irritants, vapors, and dusts}

Table 29 presents data for the gases, irritants, vapors, and dusts class. Carbon monoxide again represented the large majority of this class $(63.8 \%)$.

\section{Cough and cold preparations}

Table 30 details data on cough and cold preparations reported to the Core Registry. Dextromethorphan was again the most commonly reported agent, making up $77.5 \%$ of the class.
Table 17 Ethanol and toxic alcohols

\begin{tabular}{lc}
\hline & $N(\%)$ \\
\hline Ethanol $^{a}$ & $\mathbf{7 4 3 ( 1 0 0 )}$ \\
Nonethanol alcohols and glycols & $31(47.0)$ \\
Ethylene glycol & $21(31.8)$ \\
Isopropanol & $7(10.6)$ \\
Methanol & $7(10.6)$ \\
Miscellaneous & $b$ \\
Class total $^{b}$ & $\mathbf{6 6}(\mathbf{1 0 0 )}$ \\
\hline
\end{tabular}

${ }^{a}$ Ethanol is considered a separate agent class

${ }^{b}$ Includes diethylene glycol, denatured alcohol, ethylene glycol monohexyl ether, glycolic acid, toxic alcohol unspecified, and triethylene glycol mono butyl ether

\section{Caustics}

Table 31 presents the caustic agent class. Sodium hydroxide was the most common agent reported in this class $(17.9 \%)$ followed by sodium hypochlorite concentration unknown (14.9\%).

\section{Antimicrobials}

Table 32 presents data on antimicrobial agents. Antibiotics were the most common subclass $(57.2 \%)$, with amoxicillin representing $15.9 \%$ and miscellaneous antibiotics representing $41.3 \%$ of this class. Antivirals and other antimicrobials were less common.

Table 18 Sympathomimetic agents

\begin{tabular}{ll}
\hline & $N(\%)$ \\
\hline Methamphetamine & $228(40.3)$ \\
Cocaine & $135(23.9)$ \\
Amphetamine & $57(10.1)$ \\
Methylphenidate & $40(7.1)$ \\
Lisdexamfetamine & $31(5.5)$ \\
Dextroamphetamine & $22(3.9)$ \\
MDMA (Methylenedioxy-N-methamphetamine,Ecstasy) & $12(2.1)$ \\
Sympathomimetic unspecified & $9(1.6)$ \\
Dexmethylphenidate & $9(1.6)$ \\
Phenylephrine & $5(0.9)$ \\
Miscellaneous $^{a}$ & $18(3.2)$ \\
Class total & $\mathbf{5 6 6 ( 1 0 0 )}$
\end{tabular}

${ }^{a}$ Includes phentermine, atomoxetine, mixed amphetamine salts, clenbuterol, cathinone, norepinephrine, pseudoephedrine, and epinephrine 
Table 19 Anticholinergics and antihistamines

\begin{tabular}{ll}
\hline & $N(\%)$ \\
\hline Diphenhydramine & $301(58.6)$ \\
Hydroxyzine & $93(18.1)$ \\
Doxylamine & $22(4.3)$ \\
Benztropine & $15(2.9)$ \\
Chlorpheniramine & $13(2.5)$ \\
Promethazine & $11(2.1)$ \\
Loratadine & $9(1.8)$ \\
Pyrilamine & $8(1.6)$ \\
Cyproheptadine & $6(1.2)$ \\
Dicyclomine & $6(1.2)$ \\
Anticholinergic unspecified & $5(1.0)$ \\
Cetirizine & $5(1.0)$ \\
Miscellaneous & \\
Class total & $20(3.9)$ \\
\hline
\end{tabular}

${ }^{a}$ Includes, oxybutynin, chlorcyclizine, fexofenadine, hyoscyamine, meclizine, scopolamine, antihistamine unspecified, dimenhydrinate, trihexyphenidyl

\section{Plants and fungi}

Table S1 describes plant and fungi exposures reported to the Core Registry. In 2020 mold was again the most common single exposure (26.5\%) followed by Mitragyna speciosa (kratom) (16.3\%). Infrequent miscellaneous agents, however, made up the majority of this class $(57.1 \%)$.

\section{Hydrocarbons}

Table S2 presents the hydrocarbon agent class. The largest single contributor to the class was toluene (14.6\%), however, infrequent miscellaneous agents represented the majority $(73.2 \%)$ of the class.

\section{Gastrointestinal agents}

Table S3 presents gastrointestinal agents. Ondansetron $(25.6 \%)$, omeprazole $(12.8 \%)$, famotidine $(12.8 \%)$ and pantoprazole $(10.3 \%)$ were the most commonly reported agents.

\section{Insecticides, herbicides, rodenticides, and fungicides}

Table S4 presents the pesticide (insecticide, herbicide, rodenticide and fungicide) class. There were 13 herbicides reported (41.9\%), with glyphosate being the most common. There were $11(35.5 \%)$ insecticides and $9(29.0 \%)$ rodenticides. No fungicides were reported.

Table 20 Cardiovascular agents by type

\begin{tabular}{|c|c|}
\hline & $N(\%)$ \\
\hline Alpha-2 Agonist & $169(32.5)$ \\
\hline Clonidine & $125(24.0$ \\
\hline Guanfacine & $42(8.1)$ \\
\hline Dexmedetomidine & $2(0.4)$ \\
\hline Beta Blockers & $122(23.5)$ \\
\hline Metoprolol & $52(10.0)$ \\
\hline Propranolol & $36(6.9)$ \\
\hline Carvedilol & $19(3.7)$ \\
\hline Atenolol & $8(1.5)$ \\
\hline Miscellaneous $^{a}$ & $7(1.3)$ \\
\hline Calcium Channel Blocker & $86(16.5)$ \\
\hline Amlodipine & $51(9.8)$ \\
\hline Diltiazem & $13(2.5)$ \\
\hline Verapamil & $11(2.1)$ \\
\hline Nifedipine & $10(1.9)$ \\
\hline Nicardipine & $1(0.2)$ \\
\hline Other antihypertensives and vasodilators & $39(7.5)$ \\
\hline Prazosin & $19(3.7)$ \\
\hline Hydralazine & $8(1.5)$ \\
\hline Miscellaneous ${ }^{b}$ & $12(2.3)$ \\
\hline ACEI/ARB & $37(7.1)$ \\
\hline Lisinopril & $22(4.2)$ \\
\hline Losartan & $10(1.9)$ \\
\hline Miscellaneous $^{c}$ & $5(1)$ \\
\hline Diuretics & $23(4.4)$ \\
\hline Hydrochlorothiazide & $10(1.9)$ \\
\hline Spironolactone & $5(1.0)$ \\
\hline Furosemide & $5(1.0)$ \\
\hline Miscellaneous $^{d}$ & $3(0.6)$ \\
\hline Cardiac Glycosides & $21(4.0)$ \\
\hline Digoxin & $20(3.8)$ \\
\hline Digitoxin & $1(0.2)$ \\
\hline Antidysrhythmics and other CV Agents & $14(2.7)$ \\
\hline Amiodarone & $5(1.0)$ \\
\hline Miscellaneous $^{e}$ & $9(1.7)$ \\
\hline Antihyperlipidemic & $9(1.7)$ \\
\hline Miscellaneous $f^{f}$ & $9(1.7)$ \\
\hline Class total & $520(100)$ \\
\hline
\end{tabular}

${ }^{a}$ Includes labetalol, nadolol, and levobunolol

${ }^{b}$ Includes minoxidil, doxazosin, isobutyl nitrite, sacubitril, nitroprusside, isosorbide, and antihypertensive unspecified

${ }^{c}$ Includes valsartan, olmesartan, enalapril, and benazepril

${ }^{d}$ Includes torsemide and chlorthalidone

${ }^{e}$ Includes sotalol, flecainide, dofetilide, ranolazine, and dronedarone

${ }^{f}$ Includes atorvastatin, rosuvastatin, pravastatin, and fenofibrate

\section{Chemotherapeutic and immunological agents}

Table S5 describes chemotherapeutic and immunological agents. Methotrexate (23.3\%), hydroxychloroquine (13.3\%), and colchicine $(13.3 \%)$ were the three most commonly reported agents.

\section{Anticoagulants}

Table S6 details anticoagulant class exposures. Warfarin (36.0\%) was again the most common agent reported. 
Table 21 Antipsychotics

\begin{tabular}{ll}
\hline & $\mathrm{N}(\%)$ \\
\hline Quetiapine & $169(41.3)$ \\
Olanzapine & $54(13.2)$ \\
Risperidone & $52(12.7)$ \\
Aripiprazole & $45(11.0)$ \\
Ziprasidone & $20(4.9)$ \\
Haloperidol & $17(4.2)$ \\
Lurasidone & $12(2.9)$ \\
Clozapine & $9(2.2)$ \\
Brexpiprazole & $8(2.0)$ \\
Chlorpromazine & $7(1.7)$ \\
Paliperidone & $6(1.5)$ \\
Miscellaneous & \\
Class total & $10(2.4)$ \\
\hline
\end{tabular}

${ }^{a}$ Includes prochlorperazine, fluphenazine, thioridazine, antipsychotic unspecified, pimpozide, cariprazine, perphenazine, and droperidol

\section{Anesthetics}

Table S7 describes the anesthetic class exposures reported in 2020. Lidocaine and benzonatate (each $29.2 \%$ ) were the most commonly reported agents.

\section{Other pharmaceuticals}

Table S8 presents the other pharmaceutical products agent class. The majority of the class $(72.0 \%)$ was made up of

Table 22 Anticonvulsants and mood stabilizers

Table 23 Psychoactives

\begin{tabular}{|c|c|}
\hline & $N(\%)$ \\
\hline Molly - Amphetamine-like hallucinogen ${ }^{a}$ & $7(100)$ \\
\hline Marijuana & $78(25.5)$ \\
\hline Tetrahydrocannabinol & $62(20.3)$ \\
\hline Cannabinoid nonsynthetic & $28(9.2)$ \\
\hline Delta-9-tetrahydrocannabinol & $21(6.9)$ \\
\hline $\operatorname{LSD}^{b}$ & $19(6.2)$ \\
\hline Cannabinoid synthetic & $17(5.6)$ \\
\hline Gamma hydroxybutyrate & $15(4.9)$ \\
\hline Phencyclidine & $13(4.2)$ \\
\hline Nicotine & $12(3.9)$ \\
\hline Cannabidiol & $7(2.3)$ \\
\hline Hallucinogenic amphetamines & $6(2.0)$ \\
\hline Miscellaneous $^{c}$ & $17(5.6)$ \\
\hline Class total & $306(100)$ \\
\hline
\end{tabular}

${ }^{a}$ Amphetamine-like hallucinogens are considered a separate agent class

${ }^{b}$ LSD lysergic acid diethylamide

${ }^{c}$ Includes methylenedioxymethamphetamine, psychoactive unspecified, pharmaceutical THC, hallucinogen unspecified, gamma butyrolactone, disulfram, 1,4 butanediol

infrequently reported miscellaneous agents. Sumatriptan was the most commonly reported single agent (16.0\%).

\section{Endocrine}

Table S9 describes the 24 endocrine agents reported. Levothyroxine represented nearly half of the reported agents $(45.8 \%)$.

\begin{tabular}{ll}
\hline & $N(\%)$ \\
\hline Lithium $^{a}$ & $105(100)$ \\
Lamotrigine & $74(29.4)$ \\
Valproic acid & $49(19.4)$ \\
Oxcarbazepine & $27(10.7)$ \\
Phenytoin & $24(9.5)$ \\
Topiramate & $20(7.9)$ \\
Carbamazepine & $19(7.5)$ \\
Divalproex & $14(5.6)$ \\
Levetiracetam & $11(4.4)$ \\
Miscellaneous & \\
Class total & $14(5.6)$ \\
\hline
\end{tabular}

${ }^{a}$ Lithium is considered a separate agent class

${ }^{b}$ Includes anticonvulsant unspecified, clobazam, eslicarbazepine, felbamate, lacosamide, tiagabine, and zonisamide
Table 24 Envenomations

\begin{tabular}{ll}
\hline & $N(\%)$ \\
\hline Crotalus (Rattlesnake) & $90(35.6)$ \\
Agkistrodon (Copperhead, Cottonmouth/Water moccasin) & $87(34.4)$ \\
Snake unspecified & $43(17.0)$ \\
Loxosceles (Recluse spiders) $^{a}$ Miscellaneous $^{a}$ & $13(5.1)$ \\
Class total & $20(7.9)$ \\
\hline
\end{tabular}

${ }^{a}$ Includes Centruroides (var Scorpion incl Bark), Latrodectus (Widow spiders), Palytoxin, Vipera palaestinae, spider unspecified, Pyrrharctia isabella (isabella tiger moth), Scolopendra (var Centipede incl Giant Desert, Giant Sonoran, Texas red headed), envenomation unspecified, scorpion unspecified, Cigueterra poisoning, animal bite unspecified, and Hymenoptera (Bees, Wasps, Ants) 
Table 25 Diabetic medications

\begin{tabular}{ll}
\hline & $N(\%)$ \\
\hline Metformin & $51(39.5)$ \\
Insulin & $29(22.5)$ \\
Glipizide & $28(21.7)$ \\
Glyburide & $5(3.9)$ \\
Miscellaneous $^{\mathrm{a}}$ & $16(12.4)$ \\
Class total & $\mathbf{1 2 9}(\mathbf{1 0 0 )}$ \\
\hline
\end{tabular}

${ }^{a}$ Includes dulaglutide, empagliflozin, gliclazide, glimepiride, linagliptin, liraglutide, pioglitazone, sitagliptin, sulfonylurea unspecified.

\section{Other non-pharmaceuticals}

Table S10 describes the other non-pharmaceutical class. Water (13.0\%), silicone (13.0\%), and lactic acid (13.0\%) were the three most common agents reported.

\section{Pulmonary agents}

Table S11 describes reported pulmonary agents. Montelukast was the most common agent reported (66.7\%).

\section{Foreign bodies}

Table S12 details the foreign object ingestions reported to the Core Registry. Batteries were the most common objects (42.9\%).

\section{Anti-Parkinsonism agents}

Table S13 presents the anti-parkinsonism agent class, containing 5 entries. Reported agents included pramipexole, ropinirole, levodopa/carbidopa, and rasagiline.

Table 26 Metals

\begin{tabular}{ll}
\hline & $N(\%)$ \\
\hline Lead & $32(37.6)$ \\
Iron & $24(28.2)$ \\
Mercury & $6(7.1)$ \\
Arsenic & $6(7.1)$ \\
Miscellaneous $^{a}$ & $17(20)$ \\
Class Total $^{2}$ & $85(100)$ \\
\hline
\end{tabular}

${ }^{a}$ Includes cobalt, chromium, copper, cadmium, cilver, platinum, manganese, magnesium, cesium, and beryllium
Table 27 Herbal products and dietary supplements

\begin{tabular}{ll}
\hline & $N(\%)$ \\
\hline Caffeine & $34(38.2)$ \\
Melatonin & $21(23.6)$ \\
Miscellaneous $^{a}$ & $34(38.2)$ \\
Class total & $\mathbf{8 9 ( 1 0 0 )}$ \\
\hline
\end{tabular}

${ }^{a}$ Includes aloin (aloe vera extract or outer leaves), biotin, black cohosh, dietary supplement unspecified, eucalyptus oil, guarana, herbal (dietary) multibotanical, L-carnitine, methylxanthine, multiple vitamin, potassium, prenatal vitamin, saw palmetto, sodium chloride, vitamin B complex (undefined), vitamin B3 (niacin), vitamin B6 (pyridoxine), vitamin $\mathrm{C}$ (ascorbic acid), vitamin $\mathrm{D}$, vitamin $\mathrm{E}$ (tocopherol), yerba mate green tea extract, yohimbine, and zinc

\section{Weapons of mass destruction}

Botulinum toxin ( 5 cases) was the only agent reported in the class of weapons of mass destruction, described in Table S14.

\section{Cholinergics}

Table S15 describes the single cholinergic/parasympathetic agent reported, cholinergic/parasympathetic unspecified.

\section{Clinical signs and symptoms}

The categories of clinical signs and symptoms describe a diverse range of abnormal clinical findings. Predefined criteria must be met for each category in order for a sign or symptom to be reported as present. For example, tachycardia is defined as a heart rate greater than 140 beats per minute. Additionally, each case may report more than one abnormality within a

Table 28 Household products

\begin{tabular}{ll}
\hline & $N(\%)$ \\
\hline Cleaning solutions and disinfectants & $20(28.2)$ \\
Laundry detergent pod & $14(19.7)$ \\
Sodium hypochlorite $\leq 6 \%$ & $9(12.7)$ \\
Hand sanitizer unspecified & $6(8.5)$ \\
Miscellaneous & ${ }^{a}$ \\
Class total & $22(31.0)$ \\
\hline${ }^{a}$ Includes ammonia $\leq 10 \%$, aromatic or essential oils (carrier/solvent base \\
unspecified), diaper rash ointment, dishwasher detergent, dishwasher de- \\
tergent pod, drain cleaner (irritant), hair product, household product un- \\
specified, mequinol (4-methoxyphenol), moisturizer/lotion, oven cleaner, \\
soaps and detergents, windshield washer fluid
\end{tabular}


Table 29 Gases, irritants, vapors, and dusts

\begin{tabular}{ll}
\hline & $N(\%)$ \\
\hline Carbon monoxide & $44(63.8)$ \\
Chlorine $_{\text {Miscellaneous }^{a}}$ & $7(10.1)$ \\
Class Total & $18(26.1)$ \\
\hline
\end{tabular}

${ }^{a}$ Includes cyandide, bromide, chloramine, vaping NOS, acetonitrile, copper cyanide, cyclohexyl nitrate, duster (canned air), gases/vapors/irritants/dusts unspecified, nitrogen oxides, petroleum vapors, smoke, volatile organic compounds (VOCs) unspecified

group or across groups. For example, a single case entry may have multiple vital sign abnormalities or may have both a vital sign abnormality and a neurologic abnormality. The percentages for these categories and their individual signs and symptoms are calculated relative to the total number of Core Registry cases $(N=6668)$. It is therefore possible for the total to be more than $100 \%$.

\section{Toxidromes}

Table 33 reports the 1844 toxidromes reported to the Core Registry in 2020. Consistent with recent years, the sedativehypnotic toxidrome was the most common $(8.3 \%)$. This year the opioid toxidrome $(3.7 \%)$ overtook serotonin syndrome $(3.0 \%)$ as the third most common toxidrome reported.

\section{Major vital sign abnormalities}

Table 34 presents the 1738 vital sign abnormalities reported to the Core Registry in 2020. Trends were nearly identical to recent years. Tachycardia (11.2\%), hypotension (6.2\%), and bradycardia (3.4\%) were the most common vital sign abnormalities reported.

\section{Clinical signs and symptoms-neurologic}

Table 35 describes the 5111 neurologic clinical signs and symptoms reported to the Core Registry in 2020. Coma/

Table. 30 Cough and cold

\begin{tabular}{ll}
\hline & $N(\%)$ \\
\hline Dextromethorphan & $69(77.5)$ \\
Guaifenesin & $12(13.5)$ \\
Cough and cold unspecified & $7(7.9)$ \\
Camphor & $1(1.1)$ \\
Class total & $\mathbf{8 9 ( 1 0 0 )}$ \\
\hline
\end{tabular}

Table 31 Caustics

\begin{tabular}{ll}
\hline & $N(\%)$ \\
\hline Sodium hydroxide & $12(17.9)$ \\
Sodium hypochlorite (concentration unknown) & $10(14.9)$ \\
Cleaning agent & $8(11.9)$ \\
Caustic unspecified & $6(9.0)$ \\
Sodium hypochlorite $>6 \%^{\text {Miscellaneous }}{ }^{a}$ & $6(9.0)$ \\
Class total & $39(41.5)$ \\
\hline
\end{tabular}

${ }^{a}$ Includes acetic acid, ammonium chloride nonpharmaceutical, ammonium nitrate, boric acid (hydroborate), cement, drain cleaner, formaldehyde, hydrochloric acid, hydrogen peroxide $>10 \%$, hydroxy undecanoic acid, lithium hydroxide, peroxyacetic acid (peracetic acid), phosphoric acid, potassium hydroxide, and sulfuric acid

CNS depression (27.6\%), agitation (16.4\%), hyperreflexia/ myoclonus/clonus/tremor (10.6\%) and delirium/toxic psychosis $(10.0 \%)$ were the most commonly reported signs, similar to last year [2].

\section{Clinical signs and symptoms—cardiovascular and pulmonary}

Table 36 presents the 553 cardiovascular and 745 pulmonary clinical signs reported to the Core Registry in 2020. QTc prolongation $(5.1 \%)$ and respiratory depression $(7.8 \%)$ remained the most common signs in their respective categories again this year $[2,3]$.

Table 32 Antimicrobials

\begin{tabular}{|c|c|}
\hline & $N(\%)$ \\
\hline Antibiotics & $36(57.2)$ \\
\hline Amoxicillin & $10(15.9)$ \\
\hline Miscellaneous $^{a}$ & $26(41.3)$ \\
\hline Antivirals & $18(28.5)$ \\
\hline Tenofovir & $5(7.9)$ \\
\hline Miscellaneous $^{b}$ & 13 (20.6) \\
\hline Other Antimicrobials & 9 (14.3) \\
\hline Miscellaneous $^{c}$ & $9(14.3)$ \\
\hline Class total & $62(100)$ \\
\hline \multicolumn{2}{|c|}{$\begin{array}{l}{ }^{a} \text { Includes ciprofloxacin, clavulanic acid, clindamycin, dapsone, doxycy- } \\
\text { cline, levofloxacin, linezolid, metronidazole, minocycline, penicillin, pi- } \\
\text { peracillin, rifampin, rifaximin, tazobactam, vancomycin. }\end{array}$} \\
\hline \multicolumn{2}{|c|}{$\begin{array}{l}{ }^{b} \text { Includes acyclovir, amantadine, bictegravir, darunavir, emtricitabine, } \\
\text { ritonavir, valacyclovir. }\end{array}$} \\
\hline
\end{tabular}


Table 33 Toxidromes $^{a}$

\begin{tabular}{ll}
\hline & $N(\%)^{a}$ \\
\hline Sedative-hypnotic & $556(8.3)$ \\
Anticholinergic & $375(5.6)$ \\
Sympathomimetic & $295(4.4)$ \\
Opioid & $249(3.7)$ \\
Serotonin syndrome & $197(3.0)$ \\
Alcoholic ketoacidosis & $89(1.3)$ \\
Sympatholytic & $39(0.6)$ \\
Washout syndrome & $16(0.2)$ \\
Cannabinoid hyperemesis & $8(0.1)$ \\
NMS & $7(0.1)$ \\
Overlap syndromes & $6(0.1)$ \\
Cholinergic & $5(0.1)$ \\
Anticonvulsant hypersensitivity & $2(<0.1)$ \\
Class total & $\mathbf{1 8 4 4}(\mathbf{2 7 . 7})$
\end{tabular}

${ }^{a}$ Percentage based on the number cases reporting specific toxidrome relative to total number of Registry cases in $2020(N=6668)$

${ }^{b} N M S$ neuroleptic malignant syndrome

\section{Clinical signs - other organ systems}

Table 37 presents the other organ system clinical signs which include metabolic, renal and musculoskeletal, hematological, gastrointestinal and hepatic, and dermatological. Metabolic abnormalities were again the most frequently reported (10.4\%), and among these an elevated anion gap (4.0\%) and metabolic acidosis (4.0\%) were the most common [2, 3]. Renal and musculoskeletal abnormalities were the next most commonly reported $(7.4 \%)$, with acute kidney injury $(4.3 \%)$ being the most common sign in this subgroup. Hepatotoxicity was the most common gastrointestinal and hepatic abnormality $(2.8 \%)$. Coagulopathy was the most commonly reported hematological abnormality (1.6\%). Dermatological
Table 35 Clinical signs and symptoms - neurologic

\begin{tabular}{ll}
\hline & $\mathrm{N}(\%)^{\mathrm{a}}$ \\
\hline Coma/CNS depression & $1842(27.6)$ \\
Agitation & $1094(16.4)$ \\
Hyperflexia/Myoclonus/Clonus/Tremor & $704(10.6)$ \\
Delirium/Toxic Psychosis & $668(10.0)$ \\
Seizures & $355(5.3)$ \\
Hallucinations & $256(3.8)$ \\
Weakness/Paralysis & $61(0.9)$ \\
EPS/Dystonia/Rigidity & $58(0.9)$ \\
Numbness/Paresthesia & $56(0.8)$ \\
Peripheral Neuropathy (objective) & $17(0.3)$ \\
Class total & $\mathbf{5 1 1 1}(\mathbf{7 6 . 6 \%})$ \\
\hline${ }^{a}$ Percentages are based on the total number of cases reported to the \\
Registry in 2020 ( $N=6668) ; 3590$ Registry cases $(53.8 \%)$ reported at \\
least one neurologic clinical effect. Cases may have reported multiple \\
effects
\end{tabular}

abnormalities were less frequently reported (3.4\%), with rash being the most common (1.6\%).

\section{Fatalities}

There were 81 fatalities in 2020, comprising $1.2 \%$ of Core Registry cases. Single-agent exposures were implicated in 34 cases (Table 38), 26 cases involved multiple agents (Table 39), and in 21 cases it was unknown if there was a toxicologic exposure (Table 40).

There were 12 fatalities (14.8\%) involving opioids, an decrease from 2019 and 2018 in which opioids were reported in $19.8 \%$ and $34.0 \%$ of Core Registry deaths, respectively $[2,3]$. Fentanyl was reported in 2 deaths $(2.5 \%)$ this year compared with $5.5 \%$ in 2019 and $9.4 \%$ in 2018 [2, 3]; 3 deaths (3.7\%) were reported as single opioid ingestions in 2020 .
Table 34 Major vital sign abnormalities

\begin{tabular}{ll}
\hline & $\mathrm{N}(\%)^{\mathrm{a}}$ \\
\hline Tachycardia $(\mathrm{HR}>140)$ & $744(11.2)$ \\
Hypotension (systolic BP $<80 \mathrm{mmHg})$ & $411(6.2)$ \\
Bradycardia $(\mathrm{HR}<50)$ & $229(3.4)$ \\
Bradypnea $(\mathrm{RR}<10)$ & $166(2.5)$ \\
Hypertension $($ systolic BP $>200 \mathrm{mmHg}$ and/or diastolic BP $>120 \mathrm{mmHg})$ & $147(2.2)$ \\
Hyperthermia $\left(\right.$ temp $\left.>105^{\circ} \mathrm{F}\right)$ & $41(0.6)$ \\
Class total & $\mathbf{1 7 3 8}(\mathbf{2 6 . 1})$
\end{tabular}

$H R$ heart rate, $B P$ blood pressure, $R R$ respiratory rate

${ }^{a}$ Percentage based on the number of cases relative to the total number of Registry cases in $2020(N=6668)$. There were 1407 unique cases ( $21.1 \%$ of all Registry cases) reporting at least one major vital sign abnormality. Cases may be associated with more than one major vital sign abnormality 
Table 36 Clinical signs - cardiovascular and pulmonary

\begin{tabular}{ll}
\hline & $N(\%)^{a}$ \\
\hline Cardiovascular & \\
Prolonged QTc $(\geq 500 \mathrm{~ms})$ & $339(5.1)$ \\
Prolonged QRS ( $\geq 120 \mathrm{~ms})$ & $85(1.3)$ \\
Myocardial injury or infarction & $70(1.0)$ \\
Ventricular dysrhythmia & $45(0.7)$ \\
AV Block (> $1^{\text {st }}$ degree) & $14(0.2)$ \\
Class total & $553(8.3)$ \\
Pulmonary & \\
Respiratory depression & $517(7.8)$ \\
Aspiration pneumonitis & $107(1.6)$ \\
Acute lung injury/ARDS & \\
Asthma/Reactive airway disease & $92(1.4)$ \\
Class Total & $29(0.4)$ \\
\hline
\end{tabular}

${ }^{a}$ Percentage based on number cases reporting signs or symptoms relative to total number of Registry cases in $2020(N=6668)$. There were 1147 unique cases $(17.02 \%$ of all Registry cases) that reported at least one cardiac or pulmonary clinical effect. Cases may be associated with more than one sign or symptom

${ }^{b} A R D S$ acute respiratory distress syndrome

Acetaminophen was the most common agent involved in both single and multiple agent fatalities; there were 11 fatalities $(13.6 \%)$ involving acetaminophen, 5 as a single agent. A single death was reported after laundry pod exposure in a $>89$-year-old that sustained a corrosive gastrointestinal injury. A single agent pancrelipase death in a 7-year-old after medication administering error due to the wrong medication (either wrong route or dilution technique) was reported. A single agent lactulose death in a 2-year-old also due to a medication dosing error after receiving $75 \mathrm{~g}$ chronically was reported with respiratory depression, CNS depression, seizures, hypernatremia, and hyperglycemia. A single agent paraquat death was reported in a 60-year-old who presented with hypotension, tachycardia, QRS and QTc prolongation, and gastrointestinal bleeding. He was treated with activated charcoal, NAC, steroids, vitamin $\mathrm{C}$, and magnesium sulfate. A multi-agent death involving intentional verapamil exposure, with a subsequent lipid emulsion medication dosing error given intranasally, was reported in a 65-year-old. In addition to treatment for the verapamil exposure, she was treated with enhanced elimination and ECMO specifically related to the medication error.

In 2020 there were 13 pediatric (age $0-18$ years) deaths due to a known toxicologic exposure (16.1\%), compared with $20.0 \%$ in 2019 [2]. The age range was 13 months to 18 years. Nine were single agent exposures and 4 involved multiple agents. No pediatric exposures involved acetaminophen in
Table 37 Clinical signs - other organ systems

$N(\%)^{a}$

\section{Metabolic}

Elevated anion gap $(>20)$

$269(4.0)$

Metabolic acidosis $(\mathrm{pH}<7.2)$

$268(4.0)$

Hypoglycemia (glucose $<50 \mathrm{mg} / \mathrm{dL}$ )

105 (1.6)

Elevated osmole gap ( $>20)$

$50(0.7)$

Total

$692(10.4)^{b}$

Renal/musculoskeletal

Acute kidney injury (creatinine $>2.0 \mathrm{mg} / \mathrm{dL}$ ) 289 (4.3)

Rhabdomyolysis (CPK > $1000 \mathrm{IU} / \mathrm{L}) \quad 207$ (3.1)

Total $496(7.4)^{b}$

Gastrointestinal/Hepatic

Hepatotoxicity (AST $\geq 1000 \mathrm{IU} / \mathrm{L}) \quad 187(2.8)$

Hepatotoxicity (ALT 100-1000 IU/L) $60(0.9)$

Hepatotoxicity (ALT $\geq 1000 \mathrm{IU} / \mathrm{L}) \quad 56(0.8)$

Gastrointestinal bleeding $\quad 42(0.6)$

Pancreatitis $34(0.5)$

Corrosive injury $28(0.4)$

Intestinal ischemia $\quad 5(0.1)$

Total

$412(6.2)^{b}$

\section{Hematological}

$\begin{array}{ll}\text { Coagulopathy }(\mathrm{PT}>15 \mathrm{~s}) & 110(1.6) \\ \text { Leukocytosis }(\mathrm{WBC}>20 \mathrm{~K} / \mu \mathrm{L}) & 91(1.4) \\ \text { Thrombocytopenia }(\text { platelets }<100 \mathrm{~K} / \mu \mathrm{L}) & 83(1.2) \\ \text { Hemolysis }(\mathrm{Hgb}<10 \mathrm{~g} / \mathrm{dL}) & 63(0.9) \\ \text { Methemoglobinemia }(\mathrm{MetHgb} \geq 2 \%) & 17(0.3) \\ \text { Pancytopenia } & 8(0.1) \\ \text { Total } & \mathbf{3 7 2 ( 5 . 6 )} \\ \text { Dermatological } & \\ \text { Rash } & 107(1.6) \\ \text { Blister/Bullae } & 64(1.0) \\ \text { Angioedema } & 28(0.4) \\ \text { Necrosis } & 26(0.4) \\ \text { Total } & \mathbf{2 2 5}(\mathbf{3 . 4})^{\boldsymbol{b}}\end{array}$

$A S T$ aspartate aminotransferase, $P T$ prothrombin time, $W B C$ white blood cells, $H g b$ hemoglobin, $C P K$ creatine phosphokinase

${ }^{a}$ Percentage equals the number of cases reporting specific clinical signs compared to the total number of Registry cases in $2020(N=6668)$

${ }^{b}$ Total reflects cases reporting at least one sign in the category. Cases may be associated with more than one symptom

2020, whereas $35.7 \%$ of pediatric exposures in 2019 involved acetaminophen. Three deaths involved opioids in pediatric patients. One single agent methamphetamine death was reported in a 13-month old.

There were 46 fatality cases in which life support was withdrawn, representing $0.7 \%$ of Core Registry cases. It was unknown whether life support was withdrawn in an additional 7 cases. Brain death was declared in 19 cases. 


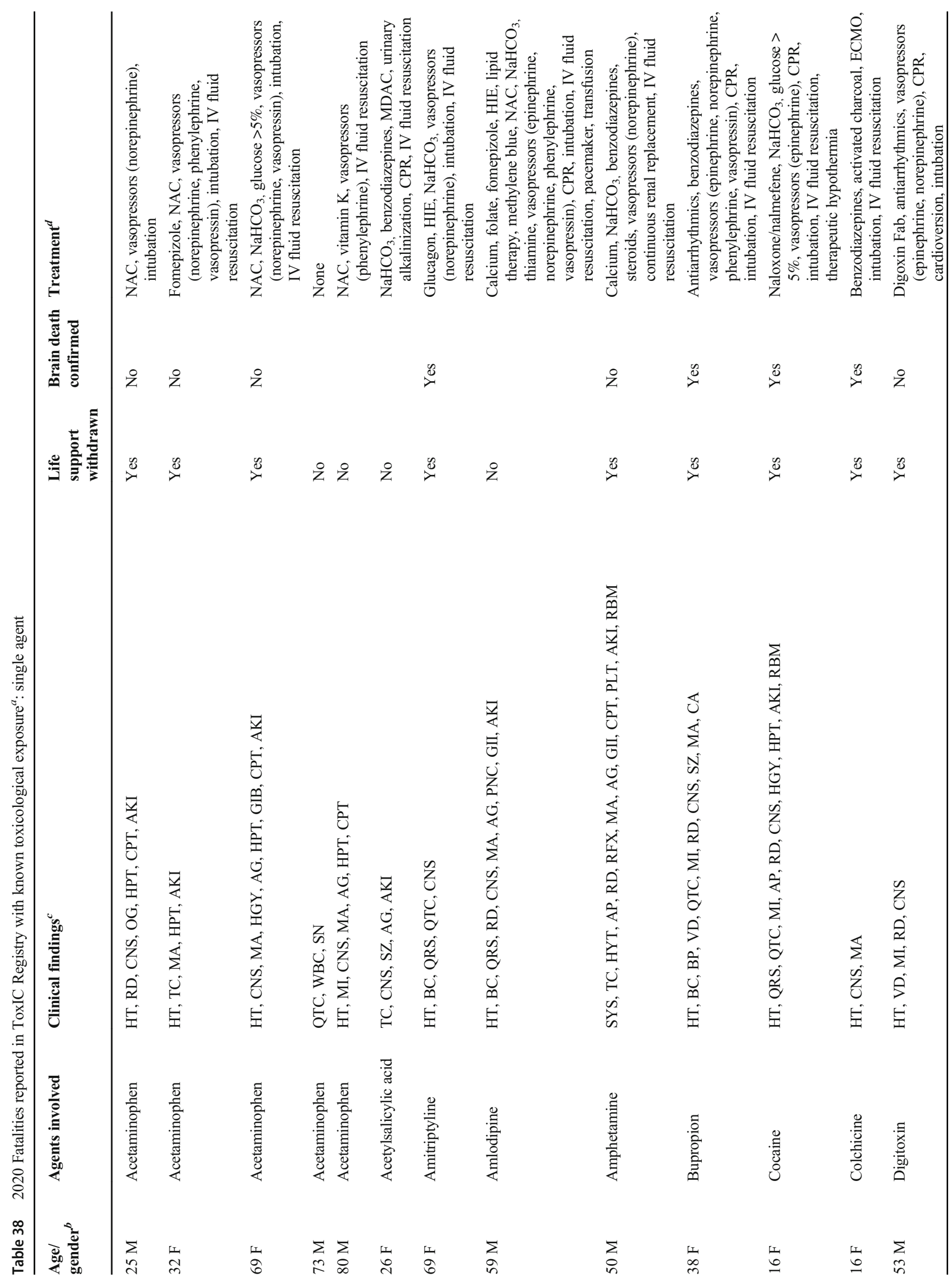




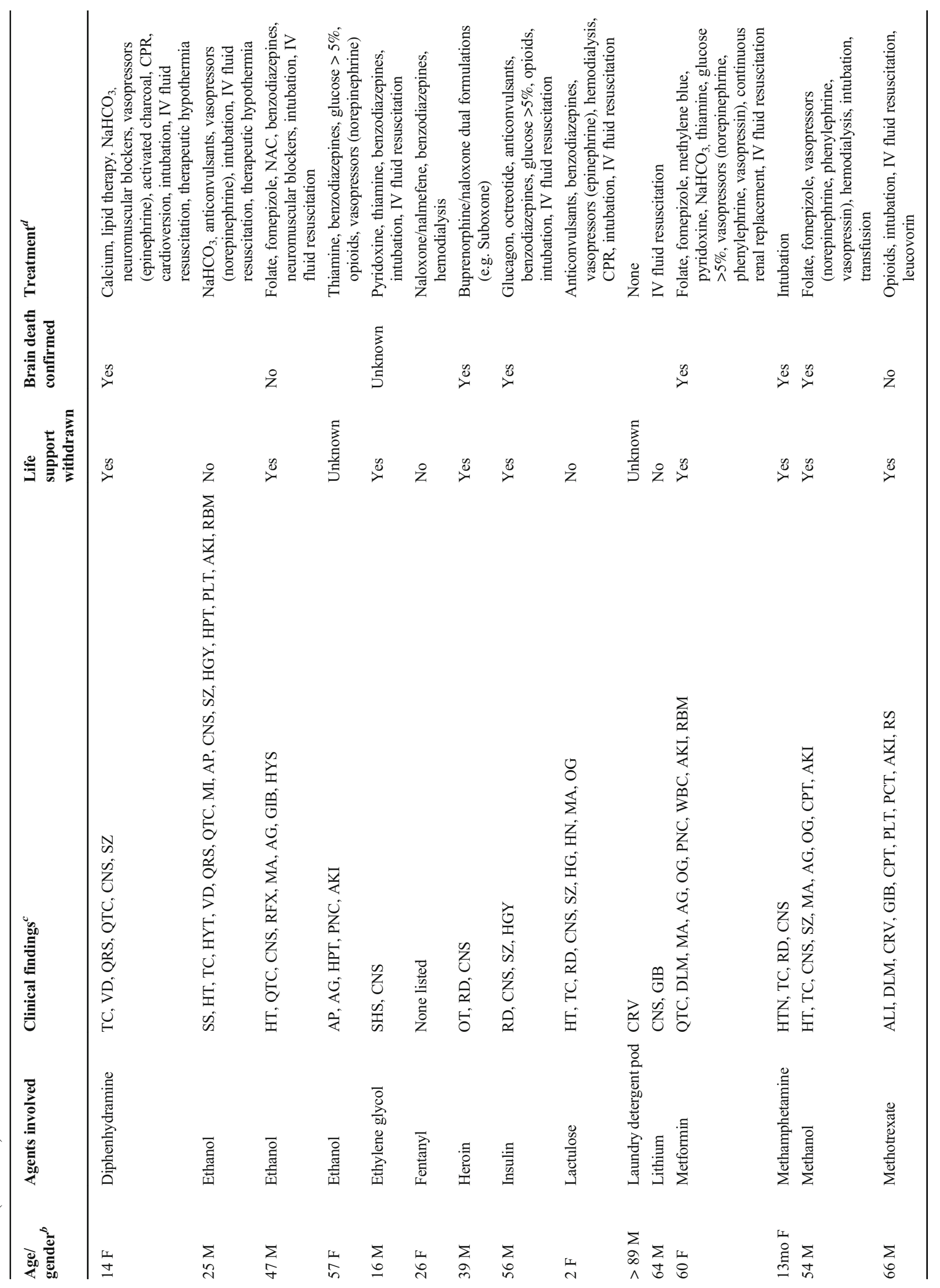




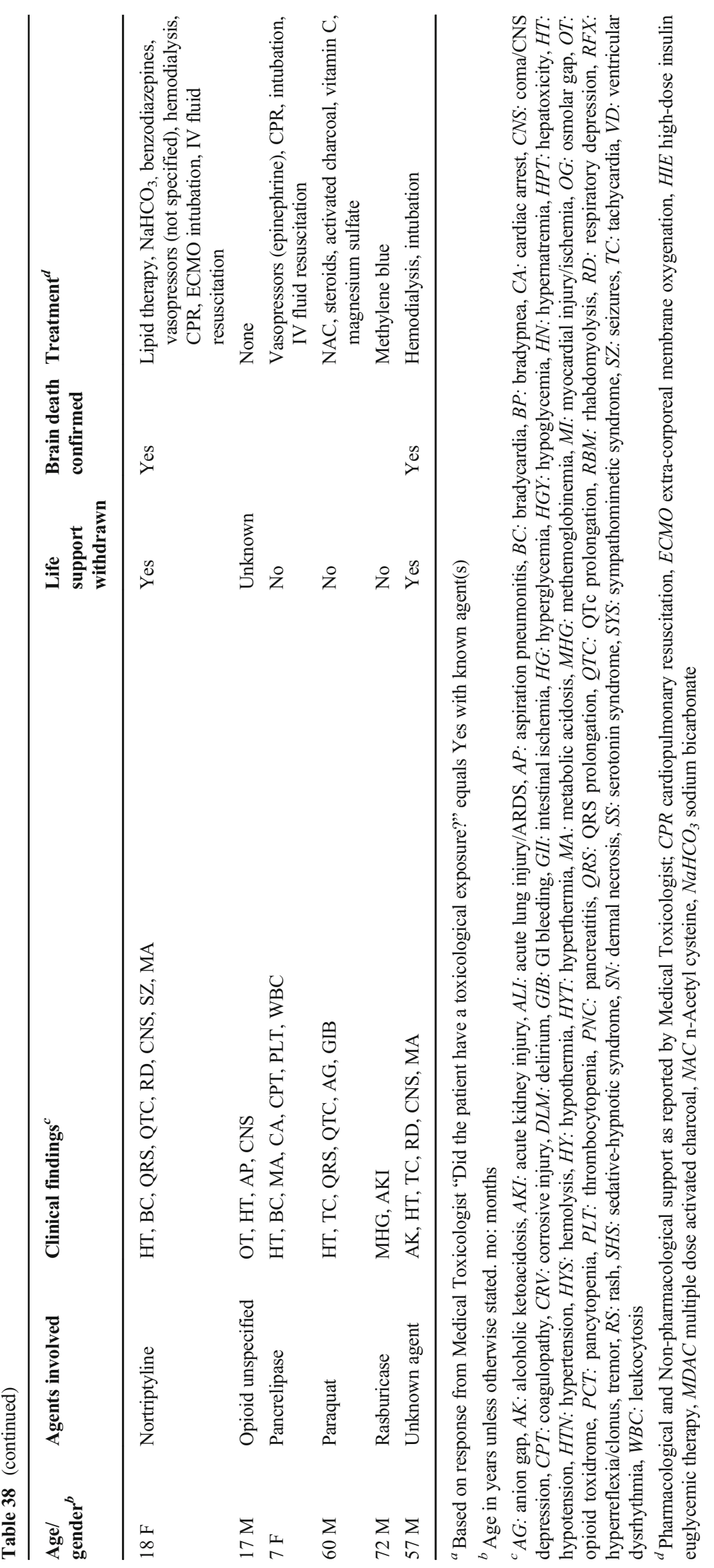




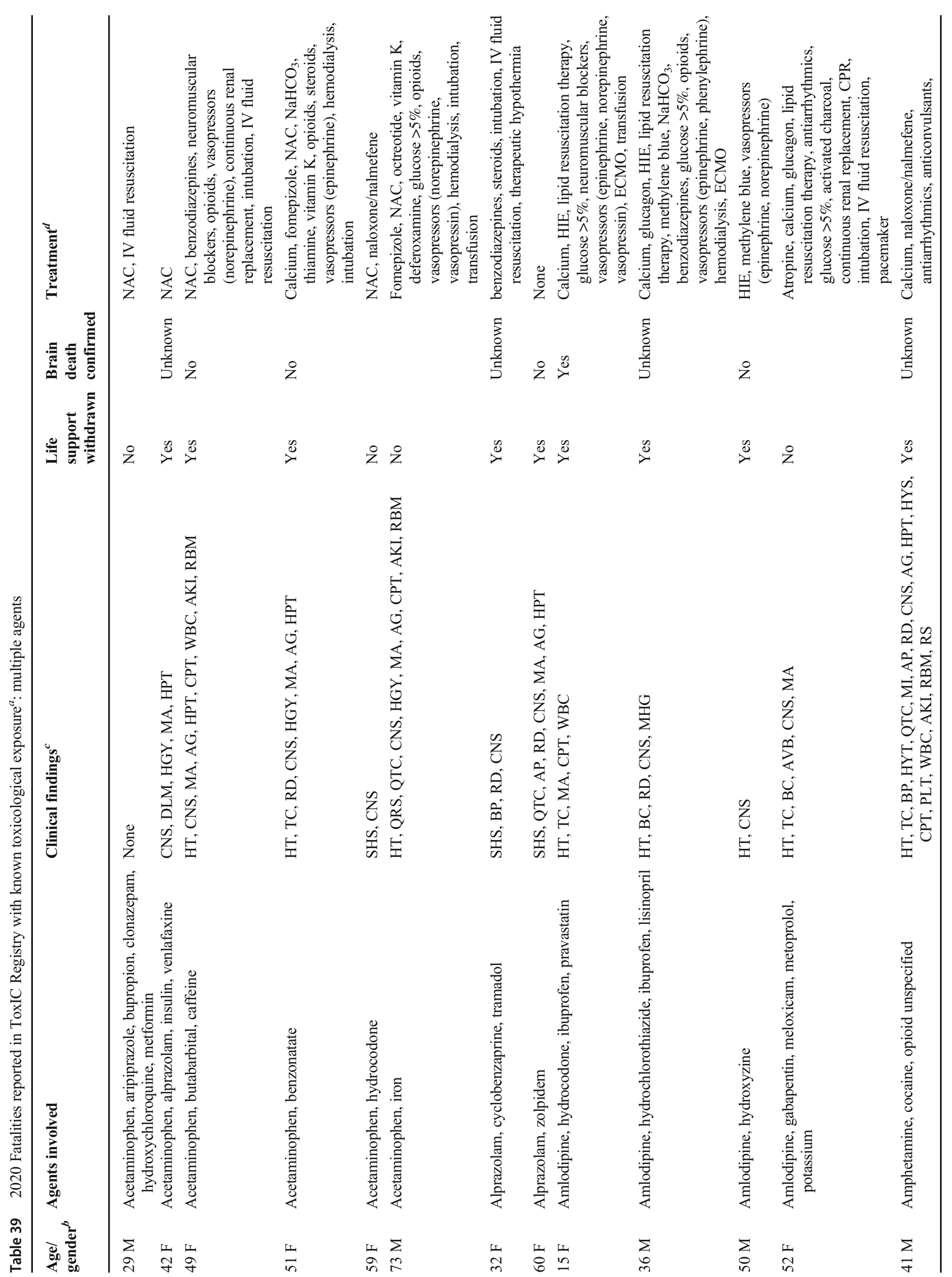




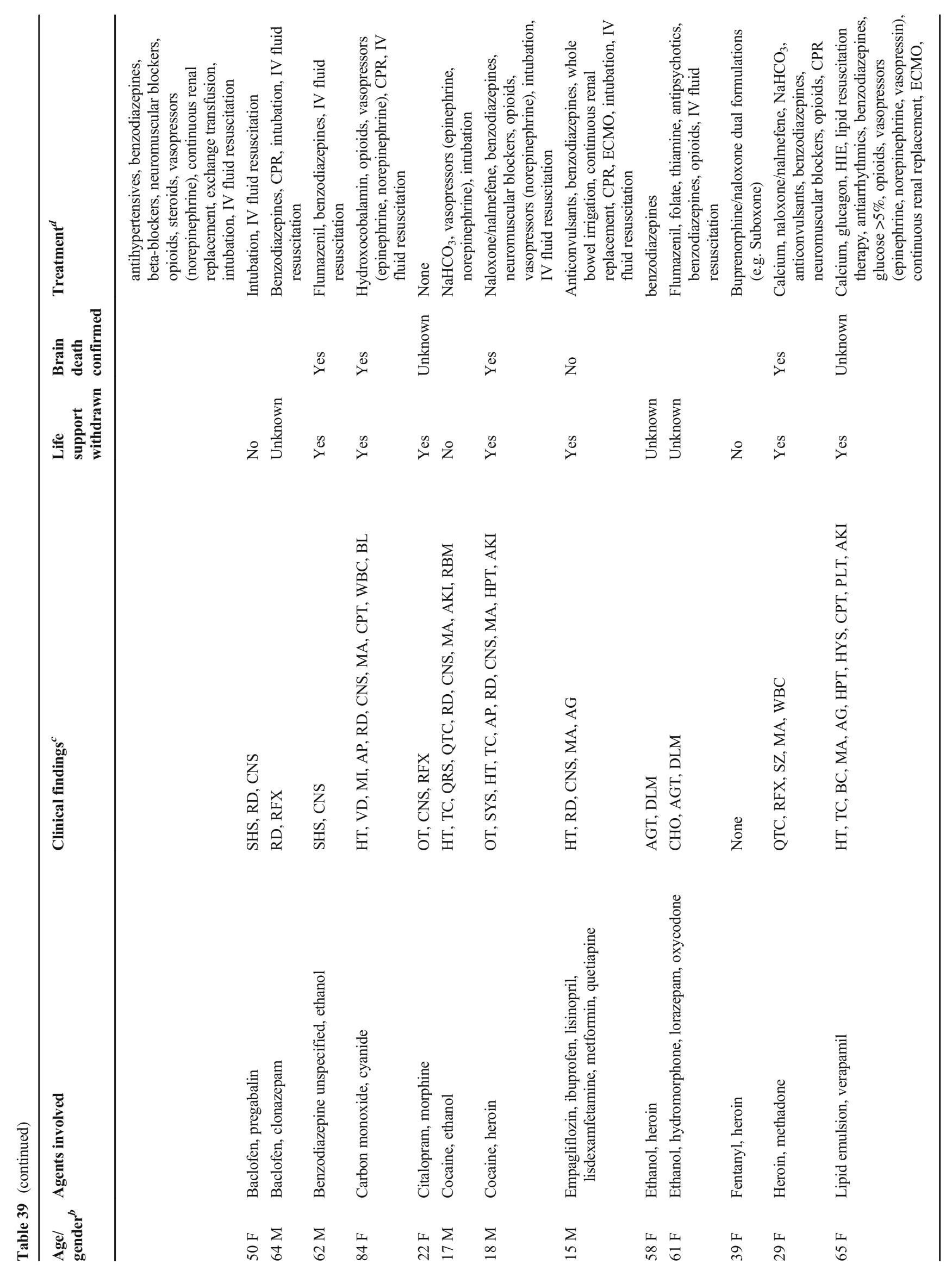


Adverse drug reactions

Table 41 presents the common drugs associated with adverse drug reactions reported to the Core Registry in 2020. One hundred seventy-seven ADRs (2.7\% of cases) were reported in 2020. Lithium was again the most common drug reported $(10.2 \%)$, similar to recent years.

\section{Treatment}

\section{Antidotal therapy}

Table 42 describes the 2777 antidotes reported to the Core Registry in 2020. Similar to last year, N-acetylcysteine (28.3\%), followed by naloxone/nalmefene (15.5\%), and thiamine $(15.0 \%)$ were the three most common antidotes reported [2]. In 2020, 31.0\% of Core Registry cases received at least one antidote compared with $26.3 \%$ in 2019 [2].

\section{Antivenom therapy}

Table 43 presents data on antivenom therapies reported to the Core Registry. Crotalidae polyvalent immune Fab (ovine) again made up the majority (65.7\%) of antivenom administered, however its relative contribution continued to decline (73.9\% in 2019 from $94.2 \%$ in 2018) in this year.[2, 3] Crotalidae immune Fab2 (equine) antivenom, introduced in 2019 (19.9\%) increased to $31.0 \%$ of cases of administered antivenom in 2020.

\section{Pharmacologic supportive care}

Table 44 describes the 3260 pharmacologic supportive care treatments reported in 2020. Benzodiazepines were again the most commonly reported agents (47.1\%), followed by opioids $(12.8 \%)$ and vasopressors $(8.1 \%)$.

\section{Non-pharmacologic supportive care}

Table 45 presents non-pharmacologic supportive care treatments reported to the Core Registry in 2020. IV fluid resuscitation $(76.1 \%)$ and intubation/ventilatory management $(19.3 \%)$, remain the most common treatments in this category.

\section{Chelation therapy administered}

Table 46 presents data on chelation therapy administered. There were 22 chelation agents reported in 2020 . Deferoxamine was the most common chelator administered (36.4\%). 


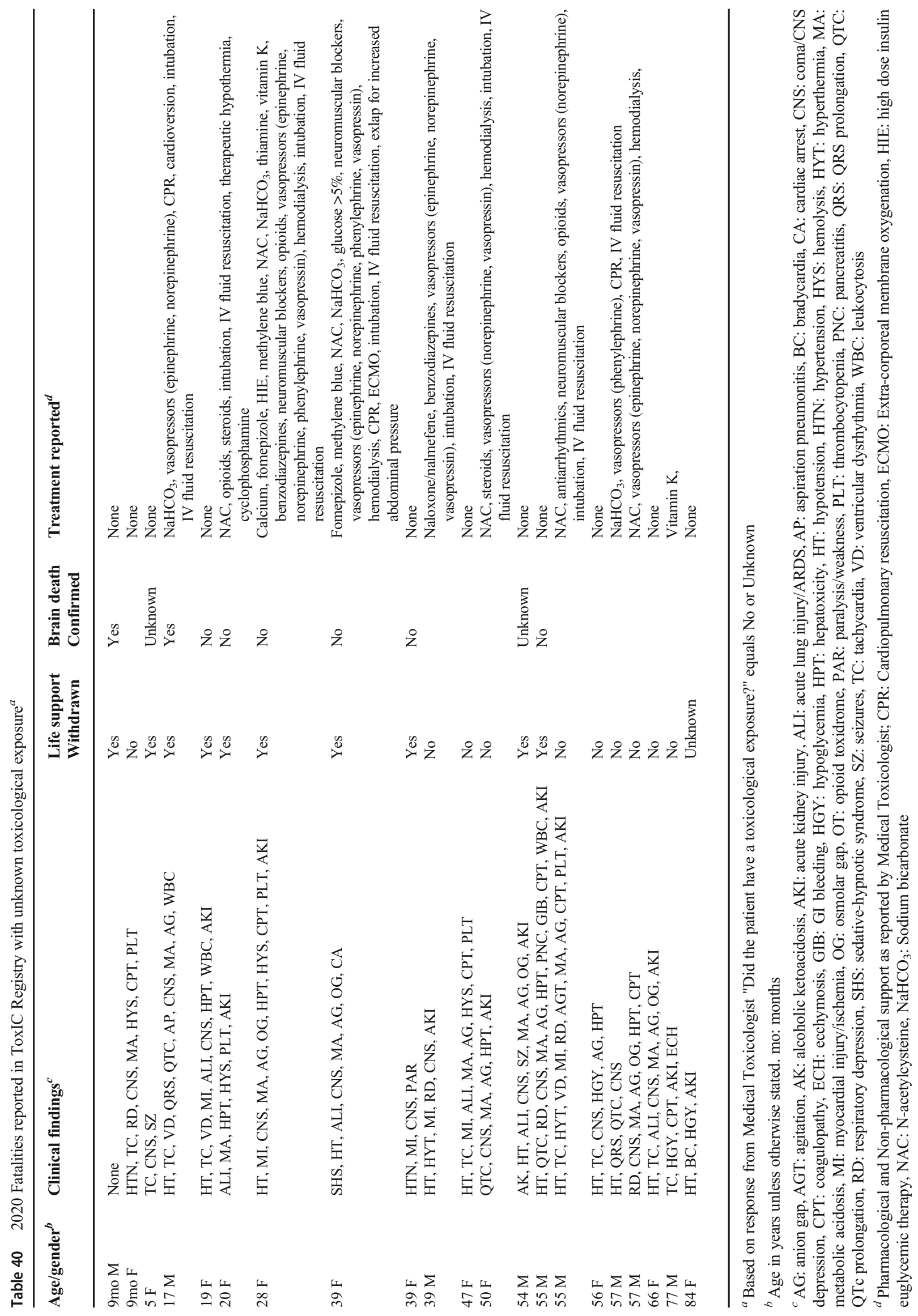


Table 41 Most common drugs associated with adverse drug reactions

\begin{tabular}{ll}
\hline & $N(\%)$ \\
\hline Lithium & $18(10.2)$ \\
Valproic acid & $6(3.4)$ \\
Baclofen & $6(3.4)$ \\
Digoxin & $5(2.8)$ \\
Quetiapine & $5(2.8)$ \\
Metformin & $5(2.8)$ \\
Miscellaneous & ${ }^{a}$ \\
Class total & $132(74.6)$ \\
\hline
\end{tabular}

${ }^{a}$ Includes gabapentin, morphine, citalopram, propofol, ondansetron, risperidone, benztropine, fluoxetine, haloperidol, guanfacine, metoprolol, phenytoin, linezolid, methadone, naloxone, olanzapine, diphenhydramine, duloxetine, lamotrigine, paliperidone, scopolamine, verapamil, aripiprazole, sertraline, carbamazepine, bupropion, amlodipine, amitriptyline, etanercept, diltiazem, amiodarone, dextromethorphan, ethinyl estradiol, ferric carboxymaltose (iron dextran), flumazenil, alprazolam, acyclovir, ethanol, arsenic, corticosteroid, bupivacaine, clozapine, dexmedetomidine, dapsone, cyproheptadine, crotalus (rattlesnake), Crotalidae Immune Fab2 (Equine, Anavip), carvedilol, chlordiazepoxide, clomipramine, clonidine, cocaine, atenolol, succinylcholine, lidocaine, pregabalin, prilocaine, rasburicase, rifampin, ropivacaine, sed-hypnotic/ muscle relaxant unspecified, piperacillin, sotalol, physostigmine, sumatriptan, tazobactam, temazepam, tramadol, triamcinolone, unknown agent, valacyclovir, vecuronium, sitagliptin, LSD, glyburide, hydromorphone, insulin, isoflurane, itraconazole, acetaminophen, lisdexamfetamine, pramipexole, lisinopril, glipizide, methotrexate, methylphenidate, metoclopramide, nadolol, nicardipine, nifedipine, nortriptyline, phenazopyridine, and ziconotide

\section{Decontamination interventions administered}

Table 47 describes the 246 decontamination interventions administered. Activated charcoal again represented the significant majority $(91.5 \%)$ in this class.

\section{Enhanced elimination interventions administered}

Table 48 presents the enhanced elimination interventions reported. Hemodialysis for toxin removal (28.4\%), continuous renal replacement therapy (25.3\%), followed by urinary alkalinization (22.1\%) and hemodialysis for other reasons (17.9\%) topped the reported interventions in this class.

\section{Discussion}

This report describes the 11th year of data collected for the Toxicology Investigators' Consortium Registry. Core Registry case numbers decreased slightly this year; however in light of the COVID-19 pandemic, that drop was not unexpected. Despite this, the Core Registry continued to grow, adding six new sites this year and increasing quality control measures.
Table 42 Antidotal therapy

\begin{tabular}{|c|c|}
\hline & $N(\%)^{a}$ \\
\hline $\mathrm{N}$-acetylcysteine & $788(28.4)$ \\
\hline Naloxone/nalmefene & $431(15.5)$ \\
\hline Thiamine & $147(14.1)$ \\
\hline Folate & $371(13.4)$ \\
\hline Sodium bicarbonate & $199(7.2)$ \\
\hline Fomepizole & $95(3.4)$ \\
\hline Physostigmine & $83(3.0)$ \\
\hline Calcium & $59(2.1)$ \\
\hline Flumazenil & $43(1.5)$ \\
\hline Cyproheptadine & $38(1.4)$ \\
\hline Glucagon & $36(1.3)$ \\
\hline Atropine & $34(1.2)$ \\
\hline Octreotide & $30(1.1)$ \\
\hline Insulin-Euglycemic therapy & $27(1.0)$ \\
\hline Carnitine & $22(0.8)$ \\
\hline Vitamin $\mathrm{K}$ & $18(0.6)$ \\
\hline Lipid resuscitation therapy & $17(0.6)$ \\
\hline Pyridoxine & $17(0.6)$ \\
\hline Methylene blue & $16(0.6)$ \\
\hline Fab for digoxin & $10(0.4)$ \\
\hline Hydroxocobalamin & $8(0.3)$ \\
\hline Dantrolene & $5(0.2)$ \\
\hline Botulinum antitoxin & $4(0.1)$ \\
\hline Anticoagulation reversal & $2(0.1)$ \\
\hline Bromocriptine & $2(0.1)$ \\
\hline Thiosulfate & $2(0.1)$ \\
\hline 2-PAM & $1(<0.1)$ \\
\hline Ethanol & $1(<0.1)$ \\
\hline Silimarin & $1(<0.1)$ \\
\hline Class total & $2777(100)$ \\
\hline
\end{tabular}

${ }^{a}$ Percentages are based on the total number of antidotes administered $(N$ $=2777) ; 2066(31.0 \%)$ cases received at least one antidote. Cases may have involved the use of multiple antidotes

Although the Core Registry is not strictly population based, it represents a wide geographic distribution of cases evaluated by medical toxicologists. These data can be used in conjunction with data from other registries including the National Poison Data System to provide a more detailed picture of poisoning trends, novel exposures, and their public health implications.

This 11th annual report finds overall trends in agent classes, agents, demographics, types of encounters, clinical signs and symptoms, and treatments to be largely unchanged from recent years. Notable findings or trends in the Core Registry are discussed below.

In 2019, the opioid class jumped to the second most common agent class reported to the Core Registry; this trend 
Table 43 Antivenom therapy

\begin{tabular}{ll}
\hline & $N(\%)^{\mathrm{a}}$ \\
\hline Crotalidae polyvalent immune fab (ovine) & $142(65.7)$ \\
Crotalidae immune fab ${ }_{2}$ (equine) & $67(31.0)$ \\
Other snake antivenom & $4(1.9)$ \\
Scorpion antivenom & $2(0.9)$ \\
Spider antivenom & $1(0.5)$ \\
Class total & $\mathbf{2 1 6 ( 1 0 0 )}$ \\
\hline
\end{tabular}

${ }^{a}$ Percentages are out of the total number of antivenom treatments administered $(N=216)$

continued again this year. Despite that increase, relative percentage of reported opioid-related deaths has fallen over the last several years (14.8\% vs $19.8 \%$ vs $34.0 \%$ for 2020,2019 , and 2018, respectively).[2, 3]

Relative contribution of fentanyl to the opioid class exposures continues to increase ( $25.4 \%$ vs $14.6 \%$ vs $10.1 \%$ for 2020,2019 , and 2018, respectively) $[2,3]$ and remains the second most common opioid reported in 2020. Oral opioids such as oxycodone, methadone, buprenorphine, tramadol, and hydrocodone remained relatively stable this year.

In 2020 ethanol became the 4th most common agent class reported, overtaking the sedative hypnotic/muscle relaxant class.

Marijuana and THC/CBD-related products continues to represent the majority of the psychoactive class $(65.7 \%)$ and relative contribution of synthetic cannabinoid cases continued to fall.

Table 44 Supportive care-pharmacologic

\begin{tabular}{ll}
\hline & $N(\%)^{\mathrm{a}}$ \\
\hline Benzodiazepines & $1535(47.1)$ \\
Opioids & $418(12.8)$ \\
Vasopressors & $263(8.1)$ \\
Phenobarbital & $249(7.6)$ \\
Antipsychotics & $217(6.7)$ \\
Glucose > 5\% & $113(3.5)$ \\
Neuromuscular blockers & $111(3.4)$ \\
Anticonvulsants & $110(3.4)$ \\
Antihypertensives & $73(2.2)$ \\
Steroids & $65(2.0)$ \\
Albuterol and other bronchodilators & $39(1.2)$ \\
Beta-blockers & $34(1.0)$ \\
Antiarrhythmics & $31(1.0)$ \\
Miscellaneous & ${ }^{a}$ \\
Class total & $2(0.1)$ \\
\hline
\end{tabular}

${ }^{a}$ Percentages based on the total number of pharmacologic interventions $(N=3260)$; 2243 Registry cases $(33.6 \%)$ received at least one pharmacologic intervention. Cases may have involved the use of multiple interventions
Table 45 Supportive care - non-pharmacologic

\begin{tabular}{ll}
\hline & $N(\%)^{a}$ \\
\hline IV fluid resuscitation & $2446(76.1)$ \\
Intubation/ventilatory management & $621(19.3)$ \\
CPR & $56(1.7)$ \\
Transfusion & $20(0.6)$ \\
Therapeutic hypothermia & $20(0.6)$ \\
ECMO & $19(0.6)$ \\
Cardioversion & $14(0.4)$ \\
Pacemaker & $8(0.2)$ \\
Hyperbaric oxygen & $6(0.2)$ \\
Transplant & $2(0.1)$ \\
Cardiopulmonary bypass & $1(<0.1)$ \\
Class total & $\mathbf{3 2 1 3 ( 1 0 0 )}$
\end{tabular}

${ }^{a}$ Percentages are based on the total number of treatments administered $(N$ $=3213) ; 2619$ Registry cases $(39.3 \%)$ received at least one form of nonpharmacologic treatment. Cases may have involved the use of multiple forms of treatment. CPR Cardiopulmonary resuscitation, ECMO extracorporeal membrane oxygenation

With regards to envenomations, 2020 saw new trends including an increase in relative Agkistrodon cases $34.4 \%$ in 2020 vs $16.9 \%$ in 2019). Two of the six new sites added to the Core Registry in 2020 commonly report Agkistrodon cases, possibly driving this year's trend. In addition, the use of Crotalidae immune Fab2 (equine) antivenom continued to increase this year (31.0\% in 2020 vs $19.9 \%$ 2019) [2].

\section{Telemedicine encounters}

Table 49 presents data on the 144 telemedicine encounters reported in 2020. This was the first year such data was collected in the Core Registry, prompted by the COVID-19 pandemic and national rise of telemedicine as a mode of patient care. Most evaluations were for patients physically located in the emergency department at the time of the encounter $(n=74$;

Table 46 Chelation therapy

\begin{tabular}{ll}
\hline & $N(\%)^{a}$ \\
\hline Deferoxamine & $8(36.4)$ \\
DMSA & $7(31.8)$ \\
EDTA & $5(22.7)$ \\
Dimercaprol & $2(9.1)$ \\
Class Total & $\mathbf{2 2 ( 1 0 0 )}$ \\
\hline
\end{tabular}

${ }^{a}$ Percentages are out of the total number of chelation treatments administered $(\mathrm{N}=22)$; 20 Registry cases $(0.3 \%)$ received at least one form of chelation treatment. DMSA dimercaptosuccinic acid, EDTA ethylenediamine-tetraacetic acid 
Table 47 Supportive care-decontamination

\begin{tabular}{ll}
\hline & $N(\%)^{a}$ \\
\hline Activated charcoal & $225(91.5)$ \\
Whole bowel irrigation & $14(5.7)$ \\
Irrigation & $5(2.0)$ \\
Gastric lavage & $2(0.8)$ \\
Class total & $\mathbf{2 4 6 ( 1 0 0 )}$ \\
\hline
\end{tabular}

${ }^{a}$ Percentages based on the total number of decontamination interventions $(N=246)$; 240 Registry cases $(3.6 \%)$ received at least one decontamination intervention. Cases may have involved the use of multiple interventions

$51.4 \%)$. Sixty-five (45.1\%) occurred via telemedicine instead of in person because of concerns for infection, while 14 $(9.7 \%)$ were due to a hospital policy. COVID-19 status was only known in $19(13.2 \%)$ patients; 3 were positive and 16 were negative. Half of the telemedicine consults consisted of chart reviews $(50.7 \%)$.

Only seven evaluations (4.9\%) were primarily addiction medicine evaluations, five of which were for initiation of opioid agonist therapy. No telemedicine evaluations were for adverse drug reactions or medication errors. Toxicology therapeutic intervention was administered to 94 (65.3\%) patients, but only $75(52.1 \%)$ of telemedicine evaluations were billed.

\section{COVID}

A new set of COVID-19 specific questions were incorporated into the ToxIC Core Registry on August 1, 2020. After this implementation, a total of 3119 toxicological exposure cases were reported in 2020. Fifty-one cases (1.6\%) were COVID-19 positive, 1397 (44.8\%) were COVID-19 negative, and 1671 (53.6\%) were unknown. Regarding the COVID-19 cases, males represented $54.9 \%$; there were no transgender COVID-19-positive patients. Age and gender breakdown of

Table 48 Enhanced elimination

\begin{tabular}{ll}
\hline & $N(\%)^{a}$ \\
\hline Hemodialysis (toxin removal) & $54(28.4)$ \\
Continuous renal replacement therapy & $48(25.3)$ \\
Urinary alkalinization & $42(22.1)$ \\
Hemodialysis (other indication) & $34(17.9)$ \\
Multiple-dose activation charcoal & $11(5.8)$ \\
Exchange transfusion & $1(0.5)$ \\
Class total & $\mathbf{1 9 0 ( 1 0 0 )}$ \\
\hline
\end{tabular}

${ }^{a}$ Percentages are based on the total number of treatments administered $(N$ $=190) ; 168$ Registry cases $(2.5 \%)$ received at least one form of enhanced elimination

Table 49 Telemedicine encounters

$\mathrm{N}(\%)$

\begin{tabular}{ll} 
Source of referral & \\
ED $^{\mathrm{a}}$ & $74(51.4)$ \\
Admitting service & $50(34.7)$ \\
Poison center & $1(0.7)$ \\
Outside hospital transfer & $3(2.1)$ \\
Nature of consultation & \\
Consult from ED or inpatient service & $126(87.5)$ \\
Admitting toxicology service & $5(3.5)$ \\
Outpatient clinic & $13(9.0)$ \\
Nature of telemedicine consult & \\
Chart review & $73(50.7)$ \\
Over the phone & $16(11.1)$ \\
Over video/Internet & $54(37.5)$ \\
Unknown & $1(0.7)$ \\
Reason for encounter & \\
Attempt at self-harm & $38(26.4)$ \\
ETOH ${ }^{\mathrm{b}}$ withdrawal & $3(2.1)$ \\
Opioid withdrawal & $1(0.7)$ \\
Occupational evaluation & $5(3.5)$ \\
Interpretation of laboratory data & $3(2.1)$ \\
Organ system dysfunction & $5(3.5)$ \\
Envenomation & $9(6.3)$ \\
Total telemedicine encounters & $\mathbf{1 4 4}(\mathbf{1 0 0})$ \\
\hline
\end{tabular}

${ }^{a} E D$ emergency department

${ }^{b}$ ETOH ethanol

COVID-19 cases are described in Table 50. The toxic exposures in COVID-19 patients were largely unrelated to COVID-19; only $5(9.8 \%)$ exposures were related to COVID-19 treatment or prophylaxis. Of the patients presenting with a toxic exposure, the four most common reasons for encounter include intentional pharmaceutical (50.9\%), intentional non-pharmaceutical (15.7\%) and unintentional pharmaceutical $(9.8 \%)$ and withdrawal of ethanol or opioids $(9.8 \%)$.

Table 50 Encounters for toxic exposures in COVID-19 positive patients by age and gender

\begin{tabular}{llll}
\hline & Female $N(\%)^{a}$ & Male $N(\%)^{a}$ & Total N $(\%)^{a}$ \\
\hline Age 2-6 & $2(3.9)$ & $1(2.0)$ & $3(5.9)$ \\
Age 7-12 & $1(2.0)$ & $1(2.0)$ & $2(3.9)$ \\
Age 13-18 & $7(13.7)$ & $7(13.7)$ & $14(27.4)$ \\
Age 19-65 & $10(19.6)$ & $18(35.3)$ & $28(54.9)$ \\
Age 66-89 & $3(5.9)$ & $1(2.0)$ & $4(7.8)$ \\
Class total & $23(45.1)$ & $28(54.9)$ & $51(100)$ \\
\hline
\end{tabular}

${ }^{a}$ Percent based on total number of cases $(N=51)$ 
Table 51 Reasons for encounter and primary agent in toxic exposures related to COVID-19 treatment and prophylaxis

\begin{tabular}{llllll}
\hline Age & Gender & Reason for encounter & $\begin{array}{l}\text { Self- } \\
\text { harm }\end{array}$ & Agent(s) & Treatment \\
\hline 27 & M & Intentionally taking higher dose than indicated & Yes & Benzonatate, ibuprofen, EtOH & None \\
49 & M & Intentionally taking higher dose than indicated & No & Acetaminophen & NAC \\
50 & M & Intentionally taking higher dose than indicated & No & Acetaminophen & NAC \\
29 & M & Accidental supratherapeutic dosing by parent & No & Acetaminophen & NAC \\
60 & M & Intentionally taking higher dose than indicated & No & Acetaminophen & NAC \\
\hline
\end{tabular}

$\mathrm{NAC}=\mathrm{N}$-acetylcystine

Agent exposures related to COVID-19 treatment or prophylaxis are described in Table 51. There were no children in this group. Only one case was related to a self-harm attempt. The remaining cases were intentional (3/4) or unintentional (1/4) supratherapeutic dosing. Acetaminophen was the most common agent ( 4 of 5 cases; $80.0 \%$ ); all acetaminophen cases required NAC treatment and $3 / 4$ developed a transaminitis.

\section{Limitations}

The ToxIC Core Registry is a unique prospective database of cases in which bedside or telemedicine consultation is performed by medical toxicologists, enabling an informed relationship between exposures and clinical outcomes. Limitations, however, do exist for the Core Registry. One of these is a bias towards inclusion of more severe case presentations, as cases are only included if they undergo subspecialty consultation. Cases for which a medical toxicology consultation was not requested are not reported and may represent a group with less severe illness. Therefore, the Core Registry likely represents a different population from other data sources such as Poison Control Centers. Regional differences may lead to a disproportionate number of specific cases reported based on variations in drug use, abuse, and other toxic exposures. The ToxIC Core Registry includes sites from multiple, diverse locations, but the entire country is not uniformly represented. Larger academic medical centers with greater amounts of medical toxicology faculty may be over-represented in the database.

At the level of the individual sites, there may be a reporting bias towards more complicated or interesting cases. Although the express intent of the Core Registry, as defined in written agreements with all sites, is to obtain a consecutive sample of all cases at a given site, individual cases may be missed. Data regarding substances of exposure or species of envenomation relies heavily on patient self-report and may be misclassified; this limitation is likely of most significance with regard to illicit drug exposure and patient hesitancy to disclose detailed information. Lastly, efforts are made to continually improve the quality of data collected. While member sites are instructed to complete all applicable data fields, there are still a number of cases and data fields with incomplete information. This remains an issue for collection of race and ethnicity, for example. Efforts continue to support quality data collection and follow up on missing data where applicable.

\section{Conclusions}

The ToxIC project continues to grow and evolve, including the Core Registry and additional surveillance projects. The Core Registry remains unique amongst databases in that it represents prospective data collected from cases evaluated by medical toxicologist specialists. Although this feature limits extrapolation to the population as a whole, it increases the potential for high-quality data and for increased correlation between exposure cases and clinical findings. Continued quality improvement and surveillance efforts remain areas of focus for the Core Registry and of ToxIC as a whole.

Supplementary Information The online version contains supplementary material available at https://doi.org/10.1007/s13181-021-00854-3.

Funding sources The Toxicology Investigators Consortium received funding from the US National Institute of Drug Abuse (1RO1DA037317- 02) and the American Academy of Addiction Psychiatry (1H79TI083343) and has data-sharing contracts with the U. S. Food and Drug Administration, Centers for Disease Control and Prevention (CDC), and BTG International, Inc. (North America).

Toxicology Investigators Consortium (ToxIC) 2020 Study Group Collaborators: Acciani J, Akpunonu PD, Aks S, Algren DA, Atti S, Avera R, Baum RA, Beauchamp GA, Bentur D, Beuhler M, Boyle KL, Brenner M, Bruccoleri R, Burns M, Button B, Calello DP, Canning J, Cannon RD, Cao D, Carey JL, Carpenter J, Castaneda J, Castelli R, Cates A, Ceretto V, Chen R, Christian MR, Conner K, Cook MD, Correia M, Dargan P, De Olano J, DeGelorm T, Devgun J, Dribben W, Eisenga BE, Epperson C, Falkowitz D, Farrar HC, Feng S, Fernandez D, Fikse DJ, Filip AB, Finkelstein Y, Fisher E, Ford J, Furmaga J, Gittinger M, Goldberger DJ, Gorodetsky RM, Greene SC, Griswold M, Hail S, Hartmann RJ, Hendrickson RG, Hieger MA, Hodgman MJ, Holstege C, Hoyte C, Hughes AR, James LP, Jefri MY, Judge BS, Kao L, Katz KD, Kazzi ZN, Kiernan E, Kim H, Kirschner R, Koons AL, Kowalski JM, Kusin SG, Latch RL, Levine M, Liebelt EL, Liss DB, Liu YS, Lo 
CY, Loughran DE, Lucyk SN, Lydecker A, Makar G, Manini A, Marlin M, McFalls J, McGillis ES, McKeown N, Meaden CW, Meadors K, Mink M, Minns A, Morgan BW, Mullins ME, Nacca NE, Nanagas K, Niruntarai S, Ng P, Noble MJ, Nogar J, Obilom C, Onisko N, Ontiveros S, Othong R, Pizon AF, Podmoroff H, Priya S, Quang LS, Rianprakaisang TN, Rickner-Schmidt S, Riley BD, Ross B, Roth B, Rowden A, Schaack-Rothstein L, Schauben J, Schult R, Seifert SA, Shaker K, Sharma K, Sheikh S, Simpson SE, Sollee D, Steck A, Stephani JA, Surmaitis RM, Temple C, Thompson JA, Thompson M, Thornton SL, Tormoehlen L, Ubani C, Walsh SJ, Warpinski G, Warrick BJ, Wermuth M, Wiegand TJ, Winkler G, Wolk BJ, Yarema MC, Young A, Zosel AE

We also wish to thank study coordinators: Aubin C, Beauchamp GA, Crawley LJ, Delatte S, Falter T, Fankhauser K, Garcia DA, Hieger MA, Irvin E, Krueger JA, Kurt A, Lymon KJ, Othong R, Padilla-Jones A, Phan T

Sources of funding US National Institutes of Health

US Food and Drug Administration

BTG International

Center for Disease Control and Prevention (CDC)

\section{Declarations}

Conflict of interest The authors have no conflicts of interest to declare.

Previous presentation of data This data has not been previously presented.

\section{References}

1. Brent J, Wax PM, Schwartz T, et al. The toxicology investigators consortium case registry-the 2010 experience. J Med Toxicol. 2011;7 (4):266-76.

2. Spyres MB, Farrugia LA, Kang AM, Aldy K, Calello DP, Campleman SL, On behalf of the toxicology investigators consortium study group, et al. The Toxicology Investigators Consortium Case Registry - the 2019 Annual Report. Journal of Medical Toxicology. 2020;16(4):361-87. https://doi.org/10.1007/s13181020-00810-7.

3. Spyres MB, Farrugia LA, Kang AM, Calello DP, Campleman SL, On behalf of the Toxicology Investigators Consortium (ToxIC) Study Group, et al. The Toxicology Investigators Consortium Case Registry-the 2018 Annual Report. Journal of Medical Toxicology. 2019;15(4):228-54. https://doi.org/10.1007/s13181-019-00736-9.

4. Farrugia LA, Rhyee SH, Campleman SL, Judge B, Kao L, Pizon A, Porter L, Riederer AM, Wiegand T, Calello D, Wax PM, Brent J, On behalf of the Toxicology Investigators Consortium (ToxIC) Study Group. The Toxicology Investigators Consortium Case Registrythe 2017 Annual Report. Journal of Medical Toxicology. 2018;14(3):182-211. https://doi.org/10.1007/s13181-018-0679-z.

5. Farrugia LA, Rhyee SH, Calello DP, Campleman SL, Riederer AM, On behalf of the Toxicology Investigators Consortium Study Group, et al. The Toxicology Investigators Consortium Case Registry - the 2016 Experience. Journal of Medical Toxicology. 2017;13(3):20326. https://doi.org/10.1007/s13181-017-0627-3.

Publisher's Note Springer Nature remains neutral with regard to jurisdictional claims in published maps and institutional affiliations. 